\title{
Bacterial community succession during in situ uranium bioremediation: spatial similarities along controlled flow paths
}

\author{
Chiachi Hwang ${ }^{1,7}$, Weimin Wu ${ }^{2}$, Terry J Gentry ${ }^{3}$, Jack Carley ${ }^{4}$, Gail A Corbin ${ }^{1}$, \\ Sue L Carroll ${ }^{4}$, David B Watson ${ }^{4}$, Phil M Jardine ${ }^{4}$, Jizhong Zhou ${ }^{5,8}$, Craig S Criddle ${ }^{2}$ \\ and Matthew W Fields ${ }^{6,7,8}$ \\ ${ }^{1}$ Department of Microbiology, Miami University, Oxford, OH, USA; ${ }^{2}$ Department of Civil and Environmental \\ Engineering, Stanford University, Stanford, CA, USA; ${ }^{3}$ Department of Crop and Soil Sciences, Texas A \& M \\ University, College Station, TX, USA ${ }^{4}$ Environmental Sciences Division, Oak Ridge National Laboratory, \\ Oak Ridge, TN, USA; ${ }^{5}$ Institute for Environmental Genomics, University of Oklahoma, Norman, OK, USA; \\ ${ }^{6}$ Department of Microbiology, Montana State University, Bozeman, MT, USA; ${ }^{7}$ Center for Biofilm Engineering, \\ Montana State University, Bozeman, MT, USA and ${ }^{8}$ Virtual Institute of Microbial Stress and Survival \\ (http://vimss.lbl.gov/)
}

\begin{abstract}
Bacterial community succession was investigated in a field-scale subsurface reactor formed by a series of wells that received weekly ethanol additions to re-circulating groundwater. Ethanol additions stimulated denitrification, metal reduction, sulfate reduction and $\mathrm{U}(\mathrm{VI})$ reduction to sparingly soluble $\mathrm{U}(\mathrm{IV})$. Clone libraries of SSU rRNA gene sequences from groundwater samples enabled tracking of spatial and temporal changes over a 1.5-year period. Analyses showed that the communities changed in a manner consistent with geochemical variations that occurred along temporal and spatial scales. Canonical correspondence analysis revealed that the levels of nitrate, uranium, sulfide, sulfate and ethanol were strongly correlated with particular bacterial populations. As sulfate and $\mathrm{U}(\mathrm{VI})$ levels declined, sequences representative of sulfate reducers and metal reducers were detected at high levels. Ultimately, sequences associated with sulfate-reducing populations predominated, and sulfate levels declined as U(VI) remained at low levels. When engineering controls were compared with the population variation through canonical ordination, changes could be related to dissolved oxygen control and ethanol addition. The data also indicated that the indigenous populations responded differently to stimulation for bioreduction; however, the two biostimulated communities became more similar after different transitions in an idiosyncratic manner. The strong associations between particular environmental variables and certain populations provide insight into the establishment of practical and successful remediation strategies in radionuclidecontaminated environments with respect to engineering controls and microbial ecology.
\end{abstract}

The ISME Journal (2009) 3, 47-64; doi:10.1038/ismej.2008.77; published online 4 September 2008

Subject Category: microbial population and community ecology

Keywords: bacterial community dynamics; uranium bioreduction; uranium-reducing populations

\section{Introduction}

Uranium contamination from extraction processes for nuclear weapons production remains a significant environmental problem, and the use of depleted uranium and other heavy metals in nonnuclear weapons is an additional environmental hazard. Depleted uranium is weakly radioactive and can damage mammalian kidneys because of heavy metal toxicity (Craft et al., 2004), and the oxidized

Correspondence: MW Fields, Department of Microbiology, Center for Biofilm Engineering, Montana State University, 366 EPS Building, Bozeman, MT 59717, USA.

E-mail: matthew.fields@erc.montana.edu

Received 25 April 2008; revised 3 July 2008; accepted 9 July 2008; published online 4 September 2008 form of uranium (that is, U(VI)) is soluble, and thus mobile in groundwater. Particular microorganisms can use metals and metalloids such as U(VI) as an electron acceptor (Lloyd, 2003), and the formation of U(IV) through reduction forms a less soluble precipitate that is much less likely to contaminate water supplies. Populations within the community respond differently to disturbances and processes, and it is the cumulative effect of multiple populations directly or indirectly connected that facilitates overall activity. Therefore, work is needed to understand the relationships between biotic and abiotic parameters in the context of bioremediation.

The Field Research Center (FRC; http://www.esd. ornl.gov/orifrc/) on the Oak Ridge Reservation in eastern Tennessee was established by the US 
Department of Energy to evaluate in situ strategies for the long-term treatment of radionuclide wastes. Mixed wastes are difficult and expensive to remediate effectively with current physical and chemical technologies, but bioremediation with indigenous microorganisms holds promise as a cost-effective and comparatively unobtrusive technology for in situ remediation (Iwamoto and Nasu, 2001). Many aspects of bioremediation must be better understood for successful and efficient applications including the complex relationships between the microorganisms involved in contaminant removal, changes in pollutant concentration, and geochemical and hydrological conditions.

The study site had an initial $\mathrm{pH}$ of approximately 3.5 and was contaminated with nitrate, toxic metals and organic contaminants, which resulted from waste disposal over a 30-year period (Figure 1). During the course of the above study, we characterized changes in bacterial community structure over time and space: at the injection well (intermittent ethanol additions); at the extraction well used to capture and recycle water; at wells within the treatment zone (between the injection and extraction well) and at up- and down-gradient wells. The results demonstrate how system hydraulics and engineering control measures can impact structure and function and alter community dynamics within U(VI)-reducing communities.

\section{Materials and methods}

Site description and biostimulation tests

The well and pump system consisted of an outer groundwater recirculation loop with a nested inner recirculation loop (Figure 1). The outer loop, with recirculation between wells FW103 and FW024, created a hydraulic barrier that reduced the amount of contaminated groundwater from entering the nested inner loop (Figure 1). Within the inner loop, the carbon/electron donor (ethanol) was injected weekly into well FW104 and extracted at well FW026, and FW101 and FW102 (13.7 m depth) were the stimulated zones. Ethanol was selected based upon earlier batch microcosm experiments with field samples (Wu et al., 2006a). The recirculation flow rates in the inner loop and the outer loop (from FW103 to FW024) were $0.45 \mathrm{lmin}^{-1}$. Additional clean water was injected at well FW024 at 0.7$0.9 \mathrm{lmin}^{-1}$ to minimize entry of ambient groundwater, increase the $\mathrm{pH}$, and remove nitrate. Detailed descriptions are available elsewhere (Hwang et al., 2006; Luo et al., 2006; Wu et al., 2006a, 2007, http:// www.esd.ornl.gov/orifrc/). Stimulation of bacterial growth with ethanol began on day 137 (7 January 2004) and ended on day 754 (15 September 2005) (Wu et al., 2006b, 2007). The ethanol solution (industrial grade, $88.1 \%$ ethanol, $4.7 \%$ methanol and $7.2 \%$ water $\mathrm{w} / \mathrm{w}$ ) had a chemical oxygen
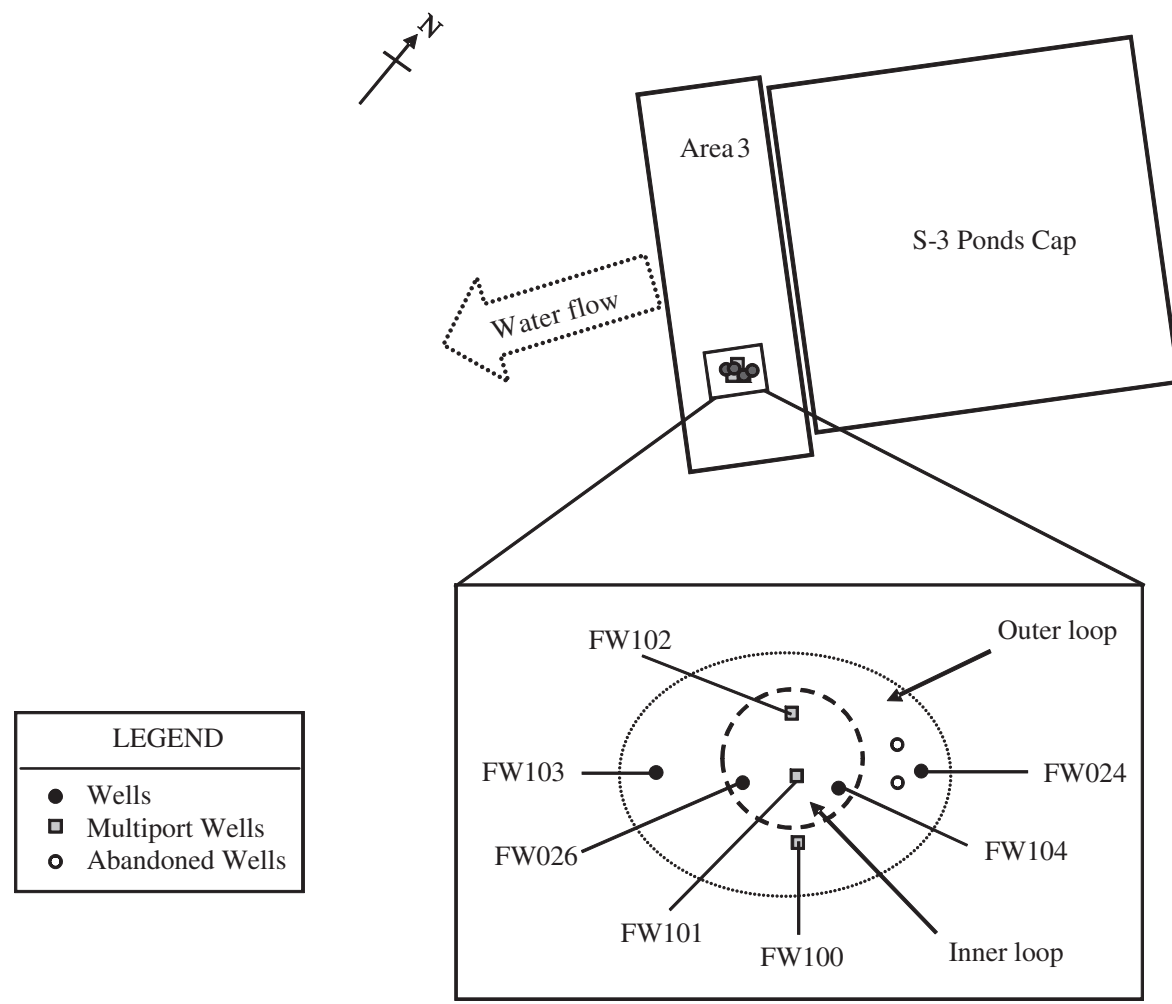

Figure 1 Schematic map of the former waste ponds at the Oak Ridge-Field Research Center in Oak Ridge, TN, USA and the inset shows location of the six sampled wells during the establishment of conditions conducive for uranium bioreduction. The substratums of the sampling sites were similar and consisted of shale with inner-embedded limestone that has been weathered to clay and silty saprolite. Water flow denotes groundwater flow. 
demand (COD)-to-weight ratio of 2.1. The solution was prepared at a COD of 6.9-9.8 $\mathrm{gl}^{-1}$ in a storage tank and injected weekly at FW104 over a 48-h period to give $120-150 \mathrm{mgl}^{-1}$ of COD at FW104 except during a starvation experiment from days 713 to 754 . The groundwater temperature fluctuated between 12 and $21^{\circ} \mathrm{C}$ because of seasonal variation over the course of the study (data not shown). For later time points, dissolved oxygen (DO) was maintained at low levels $\left(<0.03 \mathrm{mg} \mathrm{l}^{-1}\right)$ as described earlier (Wu et al., 2007).

\section{Analytical methods}

Groundwater samples were collected from the injection, extraction and monitoring wells to track biogeochemical changes. Anions (nitrate, sulfate, bromide and so on) were analyzed with an ion chromatograph (Dionex DX-120, Sunnyvale, CA, USA) as described earlier (Wu et al., 2006b). COD was used to monitor the consumption of electron donor (ethanol) and metabolic by-products (for example, acetate). COD, sulfide and $\mathrm{Fe}^{2+}$ were determined using a Hach DR2000 spectrophotometer (Hach Company, Loveland, CO, USA). U(VI) concentration was determined by kinetic phosphorescence analysis using a KPA-11 analyzer (ChemCheck Instruments, Richland, WA, USA).

\section{Sample collection, DNA extraction and DNA purification}

Groundwater was collected (approximately 2-5 l), filtered and the filters stored at $-80{ }^{\circ} \mathrm{C}$ until DNA could be extracted. Biomass collected on the filters (polycarbonate, $0.2 \mu \mathrm{m}$, Nucleopore, Whatman, Florham Park, NJ, USA) was washed, vortexed and centrifuged with $1 \times$ phosphate-buffered saline before DNA extraction. Samples were suspended in $1 \times$ phosphate-buffered saline and the cells were disrupted through two cycles of freeze-thaw and grinding in sterile sand as described earlier (Zhou et al., 1996). DNA was extracted and purified from all samples with a PowerSoil DNA Isolation Sample Kit (MO BIO, Carlsbad, CA, USA). On the basis of total cell counts and an assumed DNA amount per cell ( $\sim 5 \mathrm{fg}$ ), recovery efficiency was estimated to be $30-40 \%$ for all samples.

\section{SSU rRNA gene PCR amplification, cloning} and sequence determination

SSU rRNA gene sequences were amplified by PCR with universal bacterial primers FD1 $\left(5^{\prime}\right.$-AGAGTTT GATCCTGGCTCAG-3') and 1540R (5'-AAGGAGGT GATCCAGCC- $3^{\prime}$ ) as described earlier (Fields et al., 2005, 2006). Each 20- $\mu$ l PCR contained approximately $5-10 \mathrm{ng}^{-1} \mathrm{l}^{-1}$ of DNA, $200 \mathrm{nM}$ of each primer, $10 \mu \mathrm{l}$ of Bulls Eye Taq DNA polymerase $2.0 \mathrm{mix}$ (Midwest Scientific, St Louis, MO, USA) and an adjusted volume of sterilized water. The lowest number of PCR cycles was determined for each sample to minimize PCR-induced artifacts, and five PCRs were combined before cloning. PCR conditions were as follows: denaturation at $94{ }^{\circ} \mathrm{C}$ for $2 \mathrm{~min}$, the number of optimal cycles of $94^{\circ} \mathrm{C}$ for $30 \mathrm{~s}$, annealing at $58^{\circ} \mathrm{C}$ for $1 \mathrm{~min}$, extension at $72^{\circ} \mathrm{C}$ for $1 \mathrm{~min}$ and a final extension at $72^{\circ} \mathrm{C}$ for $7 \mathrm{~min}$. Negative PCR controls without DNA template were run concurrently for each sample. PCR products $(5 \mu \mathrm{l})$ mixed with DNA loading buffer $(2 \mu \mathrm{l})$ were visualized by agarose gel electrophoresis in a $0.8 \%$ agarose Tris-acetate EDTA gel stained with ethidium bromide. Clone libraries were constructed through a methodology to minimize possible biases introduced by PCR as described earlier (Fields et al., 2005,2006 ) and the predominant population in this study was verified with quantitative PCR (qPCR).

The PCR products were purified with a spin column purification kit (Promega, Madison, WI, USA). Clone libraries were constructed with the TOPO TA pCR2.1 cloning kit (Invitrogen, Carlsbad, CA, USA) according to the manufacturer's instructions. Transformants from each clone library were checked for inserts by PCR with M13 primers (30 cycles of the PCR conditions described above except an annealing temperature of $60{ }^{\circ} \mathrm{C}$ and a final extension time of $10 \mathrm{~min})$. The amplification products were analyzed by agarose gel electrophoresis.

PCR products from each clone were purified with a Montage $\mathrm{PCR}_{\mathrm{u} 96}$ plate according to the manufacturer's instructions (Millipore, Bedford, MA, USA). DNA sequences were determined with a Big-DYE Terminator v3.1 cycle sequencing kit (Applied Biosystems, Foster City, CA, USA) according to the manufacturer's instructions at 1:4 dilution with an internal sequencing primer (529r) as described earlier (Fields et al., 2005, 2006). Sequence reaction products were run on an ABI 3730 DNA sequencer.

\section{DNA sequence analysis}

DNA sequences were analyzed with Sequencher (v.4.0; Gene Codes Corporation, Ann Arbor, MI, USA) and vector sequences were removed. The sequences were analyzed for chimeras with Chimera-Check (Cole et al., 2003) and Bellerophon (Huber et al., 2004), and the chimeric sequences were removed from further analyses. SSU rRNA gene sequence identification was performed by comparison with known sequences in GenBank with the BLASTN server (http://www.ncbi.nlm.nih. gov/blast/Blast.cgi) and the RDP (http://rdp.cme. msu.edu/index.jsp). Unique SSU rRNA gene sequences were parsed into operational taxonomic units (OTUs) based on 97\% sequence identity. All clone sequences and reference sequences were aligned with Clustal W (Thompson et al., 1994) and phylogenetic trees were constructed with the neighbor-joining method and Jukes-Cantor distance model with bootstrap values of 500 replicates within MEGA v.4.0 (Tamura et al., 2007). 
Quantitative PCR

On the basis of clone library data, quantification of bacterial DNA for Desulfovibrio and Geobacter populations was performed with a Rotor-Gene 3000 Real-Time PCR Detection System (Corbett Life Sciences, Sydney, Australia) and Rotor-Gene Interface software (v6.0.31; Corbett Life Sciences). PCR primers Dsv691F/Dsv826R and Geo494F/Geo825R were used as described earlier (Holmes et al., 2002; Fite et al., 2004). Amplification reactions were carried out with Platinum Quantitative PCR SuperMix-UDG following the manufacturer's instructions (Invitrogen). DNA concentrations were approximately $100 \mathrm{ng}$ per reaction, and the DNA was purified before qPCR by the cetyl trimethyl ammonium bromide method. Primer concentration was optimized with genomic DNA from Desulfovibrio vulgaris and Geobacter metallireducens. The following temperature profiles were used for amplification: one cycle at $95{ }^{\circ} \mathrm{C}$ for $1 \mathrm{~min}$, followed by 40 cycles of denaturation at $95{ }^{\circ} \mathrm{C}(10 \mathrm{~s})$, primer annealing $(15 \mathrm{~s})$ at $62^{\circ} \mathrm{C}$ and extension $(30 \mathrm{~s})$ at $72{ }^{\circ} \mathrm{C}$. Quantification was performed with standard curves made from known concentrations of DNA. Melt curve analyses were performed by heating the PCR mixtures from 60 to $95{ }^{\circ} \mathrm{C}\left(1{ }^{\circ} \mathrm{C}\right.$ per cycle of $\left.10 \mathrm{~s}\right)$ with simultaneous measurements of SYBR Green signal intensities.

\section{Statistical analysis}

Rarefaction curves, OTU richness, bacterial community diversity measures (for example, ShannonWeiner $\left(H^{\prime}\right)$ index, 1/Simpson's $(1 / D)$ index and Chao1) and sample coverage for each clone library were determined by the software program DOTUR (Schloss and Handelsman, 2005) with a 3\% difference in nucleic acid sequences, and the evenness index $(E)$ was calculated within Krebs software as described earlier (Brown and Bowman, 2001). The $H^{\prime}$ index considers the equitability of the OTU distribution, $1 / D$ also considers both richness and abundance and Chao1 is a non-parametric estimation of OTU richness. However, composition and abundance may not be completely epitomized by clone distribution; therefore, measurements and indices were used for relative comparisons (Yan et al., 2003; Fields et al., 2006). Comparisons between clone libraries were made with different approaches. LIBSHUFF (http:// www.arches.uga.edu/ whitman/libshuff.html) analysis was used to construct a pairwise comparison of the SSU rRNA gene libraries as described earlier (Fields et al., 2006). UPGMA and a neighbor-joining method were used to construct phylogenetic trees with distance matrices based upon correlation values of $\Delta C_{\mathrm{xy}}$ values with MEGA v4.0 (Tamura et al., 2007).

\section{Ordination analyses}

Overall variation in bacterial community composition throughout the treatment process was charac- terized by Jackknife environmental cluster analysis and principal coordinates analysis within the UniFrac software package (Lozupone et al., 2007) according to specified instructions given at the UniFrac website (http://bmf2.colorado.edu/unifrac/ index.psp), and correspondence analysis (CA), detrended correspondence analysis and canonical correspondence analysis (CCA) were performed with Canoco v4.5 (Microcomputer Power Inc., Ithaca, NY, USA). Detrended correspondence analysis, an indirect gradient analysis technique that detrends by segments, was used to obtain the length of the gradient in the species data to allow for the selection of the appropriate method (unimodal or linear). When comparisons were made among all wells, species data were reported in percentage OTUs. When bacterial community profiles were compared between the injection and the two inner bioreduction wells only, species data were reported as percentage in bacterial families instead of percentage of OTUs. Detrended correspondence analysis revealed that the two data sets exhibited a unimodal (gradient length $=6.74$ and 3.51 for comparison between all wells and wells of the bioreduction zone, respectively) response to the explanatory variables. Thus, CCA, a direct gradient analysis, was used to examine the relationship between bacterial community profiles and environmental factors (that is, well characteristics, time, $\mathrm{pH}$, sulfate, nitrate, and subsurface manipulations). CCA has been shown to provide a flexible and meaningful constrained ordination of ecological species abundance data with environmental variables (Anderson and Willis, 2003). Partial CCA (pCCA) was also used to discern patterns related to one set of variables while controlling for a different set of variables (covariables; see Table 3).

A total of 14 explanatory variables were used when communities from all wells were analyzed: six dummy variables were assigned to characterize spatial locations (extraction, injection, and the inner and outer wells); four dummy variables were assigned to characterize engineered conditions of the subsurface (residual denitrification, ethanol stimulation without DO control, ethanol stimulation with DO control and ethanol limitation with DO control); and $\mathrm{pH}$, sulfate, nitrate and time were each considered as a variable. A total of 14 explanatory variables were used when communities from the injection and the two inner bioreduction wells were compared: three dummy variables were assigned to characterize spatial locations, four dummy variables for the engineered conditions of the subsurface as described above and pH, COD, uranium, nitrate, sulfide, sulfate and time were each considered as a variable.

Variance partitioning as described by Anderson and Gribble (1998) and Muylaert et al. (2000) was performed to determine which variables (that is, environmental, spatial or temporal) could best explain the observed distribution of species compo- 
sition (Table 3). The $P$-values for the canonical axes were produced by Monte Carlo permutation tests to determine the significance of microbial community changes in relation to environmental variables. CCA does not depend on parametric distributional assumptions and performs well with skewed species distributions (Palmer, 1993). Thus, species data were not transformed and explanatory variables were standardized.

\section{Results}

Biostimulation and U(VI) reduction

Nitrate concentrations dropped to below $0.05 \mathrm{mM}$ after day 540 once stimulation was initiated on day 137 (Figure 2). U(VI) concentrations decreased to below US EPA Maximum Contaminant Limit for drinking water $\left(0.03 \mathrm{mg} \mathrm{l}^{-1}\right)$ after day 615 in FW102. During ethanol injection, the COD concentration in wells FW104, FW101 and FW102 increased initially and then decreased as ethanol was consumed (Table 1). However, COD levels decreased to near zero when ethanol was not added from days 713 to 754. The same trend was observed for sulfide concentrations and the opposite was observed for sulfate levels. Uranium concentrations in the injection well, FW104, decreased less rapidly than the two inner bioreduction wells, FW101 and FW102.
A slight rebound in uranium concentration occurred after ethanol injection stopped, but U(VI) levels remained below $0.2 \mathrm{mg} \mathrm{l}^{-1}$.

Tracer tests with bromide indicated that the outer and inner loops were hydraulically connected. Approximately $9 \%$ of the water injected at well FW104 flowed to the outer-loop extraction well FW103, and approximately $17 \%$ of the water injected to the outer-loop well FW024 flowed to the inner-loop extraction well FW026 (Luo et al., 2007). As a result, small amounts of ethanol injected into the inner-loop leaked to the outer-loop wells.

Bacterial diversity (richness and relative abundance) A total of 23 clone libraries were constructed for the six tested wells. Approximately 80-100 clones ( $90 \pm 7$; Table 2) were analyzed for each library and approximately 2000 SSU rRNA gene sequences (approximately $500 \mathrm{bp}$ in length) were analyzed to determine population distributions over the tested time period. When a $3 \%$ OTU cutoff was used, rarefaction curves for most clone libraries approached saturation (Supplementary Figure S1), and the percent coverage for sampled diversity ranged from $63 \%$ to $93 \%$ (data not shown). The relative bacterial diversity and OTUs declined over time in well FW024 (Table 2). Although the number of sampled OTUs was initially stable in the injection
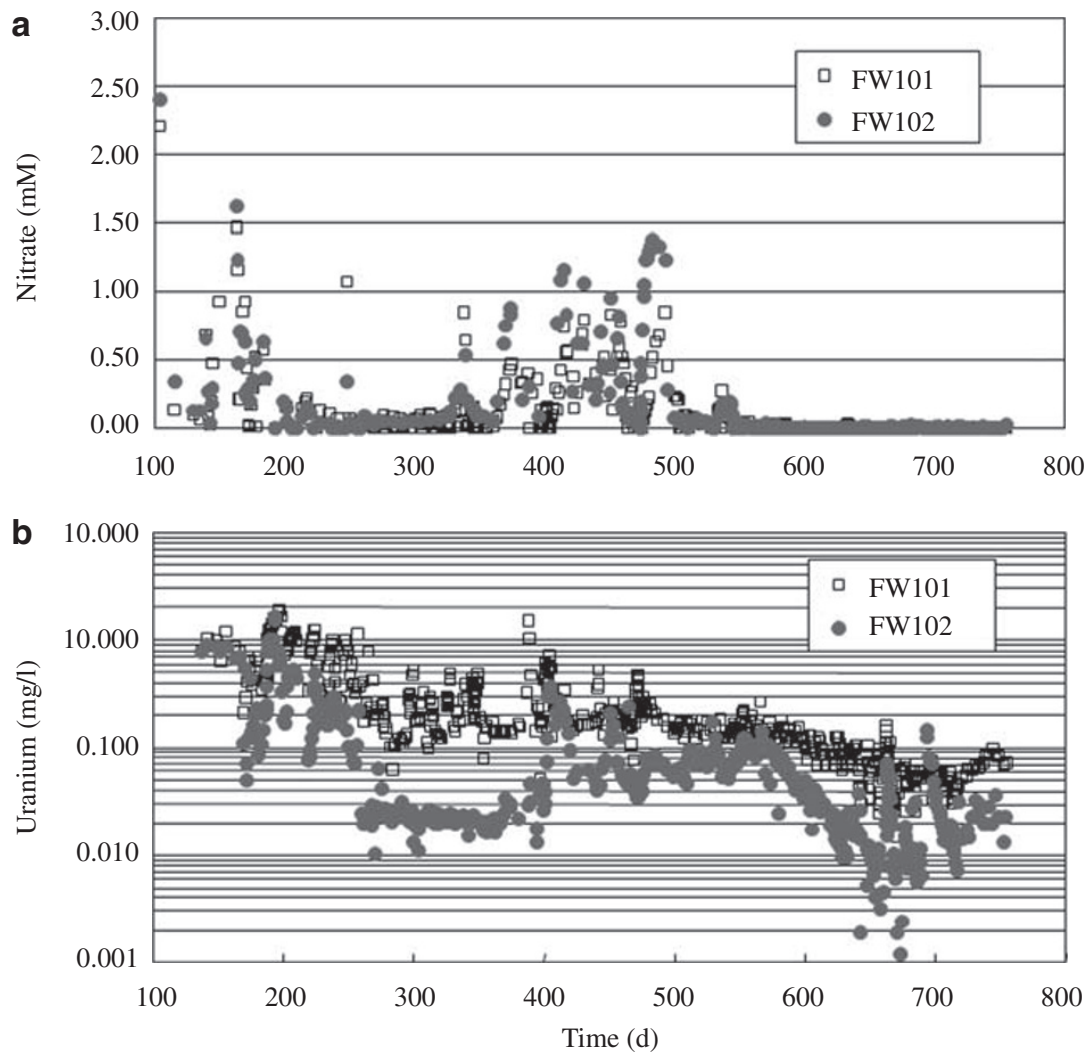

Figure 2 Nitrate (a) and uranium U(VI) concentrations (b) in groundwater of monitoring wells (FW101 and FW102) over time in the bioreduction zone. 
Table 1 Chemical properties of groundwater during the bioremediation process

\begin{tabular}{|c|c|c|c|c|c|c|c|c|}
\hline Sample number & Well & Days & $C O D\left(m g l^{-1}\right)$ & Sulfate $\left(m g l^{-1}\right)$ & Sulfide $\left(m g l^{-1}\right)$ & $p H$ & Nitrate (mM) & $U(V I)\left(m g l^{-1}\right)$ \\
\hline 1 & FW024 & 166 & 9 & 31.6 & ND & 5.89 & 0.198 & 0.50 \\
\hline 2 & & 535 & 7 & 26.3 & ND & 5.92 & 0.190 & 0.07 \\
\hline 3 & & 712 & $<2$ & 130 & ND & 5.75 & 0.015 & 0.017 \\
\hline 4 & FW104 & 166 & 40.0 & 88.0 & ND & 6.16 & 0.811 & 1.053 \\
\hline 5 & & 535 & 137 & 42.0 & 0.00 & 6.88 & 0.038 & 0.174 \\
\hline 6 & & 641 & 137 & 40.6 & 1.52 & 5.93 & 0.0017 & 0.165 \\
\hline 7 & & 712 & 119 & 58.7 & 9.34 & 5.70 & $<0.001$ & 0.142 \\
\hline 8 & & 746 & 4.00 & 111 & 0.01 & 5.77 & 0.011 & 0.137 \\
\hline 9 & FW101-2 & 166 & 17.0 & 89.3 & ND & 6.51 & 0.211 & 0.791 \\
\hline 10 & & 278 & 3.00 & 47.6 & NA & 6.43 & 0.0047 & 0.152 \\
\hline 11 & & 535 & 70.0 & 39.3 & 2.23 & 6.35 & $<0.001$ & 0.186 \\
\hline 12 & & 558 & 95.0 & 17.9 & 2.74 & 5.88 & $<0.001$ & 0.175 \\
\hline 13 & & 622 & 96.0 & 2.23 & 7.48 & 6.03 & $<0.001$ & 0.068 \\
\hline 14 & & 641 & 108 & 2.78 & 9.90 & 6.02 & 0.001 & 0.042 \\
\hline 15 & & 726 & 8.00 & 101 & 0.84 & 6.00 & $<0.001$ & 0.062 \\
\hline 16 & FW102-2 & 166 & 9.00 & 76.5 & ND & 6.33 & 0.711 & 0.696 \\
\hline 17 & & 278 & 2.00 & 27.3 & NA & 5.97 & 0.047 & 0.027 \\
\hline 18 & & 622 & 51.0 & 8.66 & 3.37 & 6.24 & $<0.001$ & 0.021 \\
\hline 19 & & 670 & 59.0 & 9.72 & 7.35 & 6.25 & $<0.001$ & 0.002 \\
\hline 20 & & 726 & 12.0 & 96.3 & 0.66 & 6.24 & $<0.001$ & 0.023 \\
\hline 21 & FW026 & 535 & 32.0 & 41.6 & 0.04 & 6.11 & 0.085 & 0.242 \\
\hline 22 & FW103 & 535 & 10 & 27.1 & ND & 6.12 & 0.147 & 0.083 \\
\hline 23 & & $<2$ & 135 & ND & 5.97 & 0.021 & 0.05 & $<2$ \\
\hline
\end{tabular}

Abbreviations: COD, chemical oxygen demand; ND, not determined; NA, not applicable.

NA denotes data not analyzed and ND denotes not determined (below detection limit).

Table 2 Characteristics and diversity estimates for SSU rRNA gene clones from groundwater samples at different time points

\begin{tabular}{|c|c|c|c|c|c|c|c|c|}
\hline Sample number & Well & Days & Number of clones ${ }^{\mathrm{a}}$ & $O T U^{\mathrm{b}}$ & $H^{\prime \mathrm{c}}$ & $1 / \mathrm{D}^{\mathrm{d}}$ & Chao-1 ${ }^{\mathrm{e}}$ & Evenness ${ }^{\mathrm{f}}$ \\
\hline 1 & FW024 & 166 & 83 & 34 & 3.13 & 17.2 & 53.1 & 0.83 \\
\hline 2 & & 535 & 84 & 31 & 2.79 & 10.4 & 73.0 & 0.76 \\
\hline 3 & & 712 & 90 & 20 & 2.26 & 6.20 & 27.3 & 0.68 \\
\hline 4 & FW104 & 166 & 84 & 24 & 2.58 & 9.35 & 69.5 & 0.74 \\
\hline 5 & & 535 & 81 & 27 & 2.66 & 8.21 & 40.0 & 0.76 \\
\hline 6 & & 641 & 80 & 24 & 2.93 & 14.3 & 29.2 & 0.80 \\
\hline 7 & & 712 & 97 & 25 & 2.89 & 16.7 & 26.2 & 0.83 \\
\hline 8 & & 746 & 89 & 41 & 3.37 & 28.4 & 95.2 & 0.84 \\
\hline 9 & FW101-2 & 166 & 84 & 16 & 1.97 & 4.56 & 19.0 & 0.64 \\
\hline 10 & & 278 & 85 & 16 & 2.24 & 7.83 & 19.0 & 0.73 \\
\hline 11 & & 535 & 83 & 33 & 3.10 & 17.1 & 50.0 & 0.83 \\
\hline 12 & & 558 & 98 & 22 & 2.25 & 5.21 & 29.5 & 0.66 \\
\hline 13 & & 622 & 98 & 35 & 3.00 & 14.3 & 70.0 & 0.78 \\
\hline 14 & & 641 & 87 & 20 & 2.55 & 11.4 & 32.0 & 0.78 \\
\hline 15 & & 726 & 92 & 23 & 2.25 & 5.09 & 42.5 & 0.64 \\
\hline 16 & FW102-2 & 166 & 103 & 28 & 2.30 & 4.81 & 47.4 & 0.63 \\
\hline 17 & & 278 & 100 & 42 & 3.16 & 15.12 & 150.8 & 0.79 \\
\hline 18 & & 622 & 98 & 39 & 3.16 & 18.35 & 126.8 & 0.81 \\
\hline 19 & & 670 & 101 & 30 & 2.57 & 8.43 & 72.0 & 0.69 \\
\hline 20 & & 726 & 95 & 52 & 3.61 & 32.13 & 101.6 & 0.93 \\
\hline 21 & FW026 & 535 & 84 & 36 & 3.10 & 16.60 & 72.1 & 0.80 \\
\hline 22 & FW103 & 535 & 85 & 24 & 2.33 & 6.46 & 48.0 & 0.67 \\
\hline 23 & & 747 & 90 & 28 & 2.49 & 6.337 & 58.6 & 0.67 \\
\hline
\end{tabular}

${ }^{a}$ Number of clones sequenced from each library.

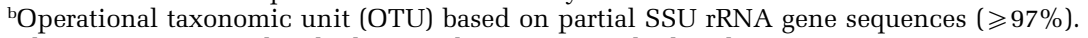

"Shannon-Weiner index, higher number represents higher diversity.

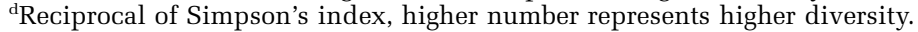

${ }^{\text {e} C h a o-1 ~ e s t i m a t e s . ~}$

${ }^{\mathrm{f}}$ Evenness index.

well FW104, an increase in sampled bacterial diversity and evenness (Table 2) was eventually observed. However, in the two bioreduction wells, FW101 and FW102, a fluctuation in diversity and evenness was observed from days 166 to 726 . In general, diversity increased during periods of ethanol addition. Diversity decreased in FW101 before implementation of DO control (maintenance of low DO, $<0.03 \mathrm{mg} \mathrm{l}^{-1}$ ), but recovered to levels comparable to those of FW102 by day 622 . 
Table 3 Summary of calculation and results of CCA conducted to partition the percent variance in the distribution of bacterial populations explained by environmental (engineering controls and subsurface geochemistry), temporal and spatial variables

\begin{tabular}{|c|c|c|c|c|c|c|c|}
\hline \multirow[t]{2}{*}{ Steps } & \multirow[t]{2}{*}{ Description } & \multicolumn{3}{|c|}{ All of the wells } & \multicolumn{3}{|c|}{ Wells of the bioreduction zone } \\
\hline & & $\begin{array}{c}\text { Sum of canonical } \\
\text { eigenvalues }\end{array}$ & $\begin{array}{l}\% \text { Variance }^{\text {explained }} \\
\text { a }\end{array}$ & P-values ${ }^{\mathrm{b}}$ & $\begin{array}{l}\text { Sum of canonical } \\
\text { eigenvalues }\end{array}$ & $\begin{array}{l}\% \text { Variance }^{-} \\
\text {explained }^{\mathrm{a}}\end{array}$ & $\mathrm{P}$-values ${ }^{\mathrm{b}}$ \\
\hline (1) & Environmental variables explanatory (CCA) & 2.450 & 33.40 & 0.002 & 1.722 & 66.90 & 0.008 \\
\hline (2) & Spatial variables explanatory (CCA) & 1.711 & 23.30 & 0.334 & 0.383 & 14.90 & 0.178 \\
\hline (3) & Temporal variables explanatory (CCA) & 0.628 & 8.60 & 0.002 & 0.435 & 16.90 & 0.002 \\
\hline (4) & Environmental variables explanatory, space as covariable (pCCA) & 2.459 & 33.50 & 0.010 & 1.613 & 62.70 & 0.018 \\
\hline (5) & Environmental variables explanatory, time as covariable (pCCA) & 2.265 & 30.80 & 0.006 & 1.416 & 55.00 & 0.072 \\
\hline (6) & Non spatially or temporally structured environmental variation (pCCA) & 2.347 & 32.00 & 0.002 & 1.290 & 50.10 & 0.114 \\
\hline (7) & Spatial variables explanatory, environment as covariable (pCCA) & 1.720 & 23.40 & 0.118 & 0.275 & 10.70 & 0.284 \\
\hline (8) & Spatial variables explanatory, time as covariable (pCCA) & 1.721 & 23.40 & 0.020 & 0.404 & 15.70 & 0.036 \\
\hline (9) & Non-environmentally or temporally structured spatial variation (pCCA) & 1.803 & 24.60 & 0.030 & 0.278 & 10.80 & 0.264 \\
\hline (10) & Temporal variables explanatory, environment as covariable (pCCA) & 0.443 & 6.03 & 0.028 & 0.130 & 5.05 & 0.382 \\
\hline (11) & Temporal variables explanatory, space as covariable (pCCA) & 0.638 & 8.70 & 0.002 & 0.456 & 17.70 & 0.002 \\
\hline (12) & Non-environmentally or spatially structured temporal variation (pCCA) & 0.527 & 7.20 & 0.038 & 0.133 & 5.20 & 0.332 \\
\hline (13) & Spatially structured environmental variation ${ }^{\mathrm{C}}$ & -0.009 & -0.12 & - & 0.109 & 4.20 & - \\
\hline (14) & Temporally structured environmental variation ${ }^{\mathrm{d}}$ & 0.185 & 2.52 & - & 0.306 & 11.90 & - \\
\hline (15) & Unexplained variation ${ }^{\mathrm{e}}$ & 2.646 & 36.00 & - & 0.444 & 17.25 & - \\
\hline
\end{tabular}

Abbreviation: pCCA, partial canonical correspondence analysis.

aThe percentage of explained variation is calculated as a proportion of the total inertia of the species data (all wells: 7.343; wells of bioreduction zone: 2.574 ).

${ }^{\mathrm{b}} P$-values based on block Monte Carlo permutation test, as described in Materials and methods.

Spatially structured environmental variation $=([1]-[4]) /$ total inertia $\times 100$.

${ }^{\mathrm{d}}$ Temporally structured environmental variation $=([1]-[5]) /$ total inertia $\times 100$.

${ }^{\mathrm{e}}$ Unexplained variation $=$ total inertia $-($ sum of canonical eigenvalues in steps $[1]+[7]+[12]) \times 100$ 
Bacterial composition and structure

For the purposes of this study, composition equates to richness and structure represents diversity. Phylogenetic analysis of the sampled SSU rRNA gene sequences revealed that bacterial communities in the groundwater changed in composition and structure throughout the different stages of treatment (Figures 3a-d). Initially, $\beta$-Proteobacteria predominated, but as ethanol stimulation continued, sequences indicative of other bacterial phyla such as $\delta$-Proteobacteria, Actinobacteria, Acidobacteria and Firmicutes became prevalent (Figure 3a). At day 166, $\beta$-Proteobacteria was the major group in the FW024, FW104, FW101 and FW102 libraries. However, as diversity increased, the $\beta$-Proteobacteria populations fluctuated in FW104, FW101 and FW102 (Figure 3a). Predominant sequences within the $\beta$-Proteobacteria were closely related to Herbaspirillum, Zooglea, Dechloromonas, Ferribacterium, Hydrogenophaga, Curvibacter and Acidovorax spp. (Supplementary Figure S2B and C). Both Zooglea and Acidovorax sequences and isolates have been observed earlier in FRC groundwater (Fields et al., 2005).

FW103 at day 535 was predominated by Rhodocyclaceae populations (49\%), and the sequences were similar to clones from FW024 on the same sampling day. Like FW024, the sampled community in FW103 also shifted to Comamonadaceae populations (51\%) at day 747 (Figure 3b). Most of the clone populations in the Comamonadaceae family had $98 \%$ sequence identity to Rhodoferax ferrireducens, whereas others had $98 \%$ sequence identity to Acidovorax delafieldii (Supplementary Figure S2B and C). Clone libraries from FW104 and FW101 were predominated by an Oxalobacteraceae population at day 166 and the clone sequences had $\geqslant 97 \%$ sequence identity to Herbaspirillum spp. (AJ012069) (Supplementary Figure S2B). FW104 shifted from predominance by an Oxalobacteraceae population $(40 \%)$ in the residual denitrification phase to predominance by Rhodocyclaceae population (most
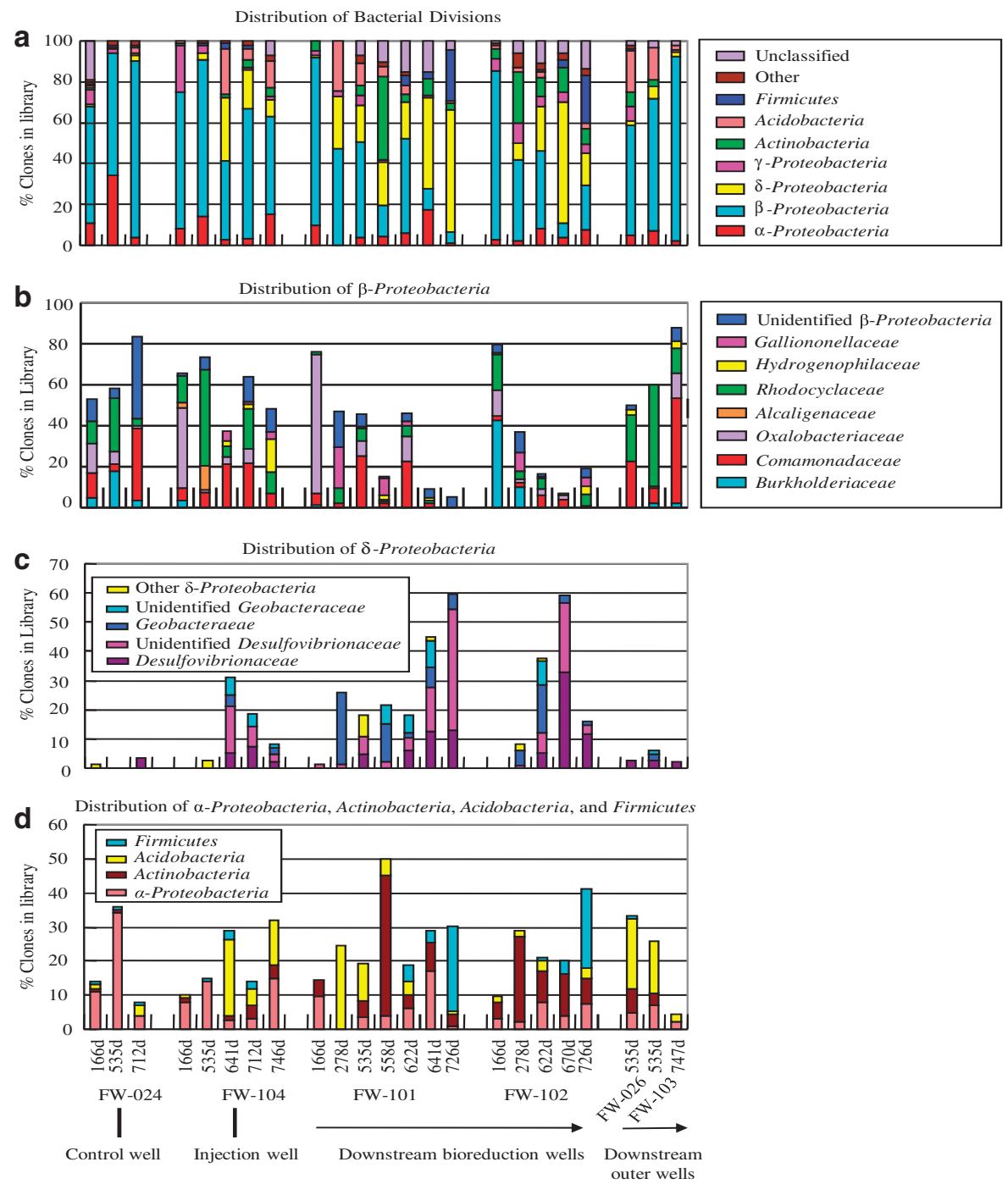

Figure 3 Distribution (\% of the total) of clones from groundwater in each well over time according to all observed (a) bacterial divisions, (b) $\beta$-Proteobacteria, (c) $\delta$-Proteobacteria and (d) $\alpha$-Proteobacteria, Actinobacteria, Acidobacteria and Firmicutes. 
closely related to an uncultivated Thauera spp. clone, DQ426920) in the uranium reduction phase before DO control (Figure 3b). The Rhodocyclaceae populations declined whereas Comamonadaceae populations increased $(22 \%)$ during the initial phase of uranium reduction with DO control, and the majority of the clone library had 98\% sequence identity to $R$. ferrireducens (Figure $3 \mathrm{~b}$ and Supplementary Figure S2B). Hydrogenophilaceae populations increased (16\%) by day 747 (Figure $3 \mathrm{~b}$ ) and the clone populations had $\geqslant 97 \%$ sequence identity to an uncultivated Thiobacillus sp. clone (EF413894) (Supplementary Figure S2A), and these results might coincide with the infiltration of oxygen.

FW101 shifted from predominance by Oxalobacteraceae $(68 \%)$ to Comamonadaceae populations $(25 \%)$ (Figure $3 \mathrm{~b})$, and the majority of the clone population had $>97 \%$ sequence identity to A. delafieldii (Supplementary Figure S2C). Gallionellaceae populations were detected at $20 \%$ and $8 \%$ of the population at days 278 and 558, respectively, but were not detected once the well entered the phases of uranium reduction with DO control and ethanol limitation. Community dynamics in well FW102 was unlike that in FW101, with predominance by Burkholderiaceae (43\%) and Rhodocyclaceae populations $(17 \%)$ at day 166 . Despite the differences in the bacterial community at day 166 , the two wells had a similar overall community structure by days 641 and 622 for FW101 and FW102, respectively (Figure 3b).

After initiation of weekly ethanol additions, $\delta$-Proteobacteria populations were detected by day 278 in wells FW101 and FW102 and by day 535 in FW104 (Figure 3c). Phylogenetic analysis of $\delta$-Proteobacteria at the family level revealed differences in each well at the respective sampling days. However, Desulfovibrionaceae and uncultivated Desulfovibrionaceae populations predominated in both wells at the end of the experiment (Figures 3c and 4). For comparison, $\delta$-Proteobacteria sequences were detected at $<3 \%$ in FW024 (outer-loop injection well), FW103 and FW026 (down-gradient wells).

Although $\delta$-Proteobacteria populations were predominant in both FW101 and FW102, the sampled communities within these wells changed over time (Figure 3a). The $\delta$-Proteobacteria populations in FW101 shifted from predominance by Geobacteraceae populations $(25 \%)$ during earlier stages of uranium reduction (day 278) to predominance by Desulfovibrionaceae during DO control (54\%). Geobacteraceae were also detected in FW102 on day 278 $(5 \%)$ and at a higher percentage on day $622(25 \%)$ during the uranium reduction phase (no DO control), but declined at the later time points $(<3 \%)$. Desulfovibrionaceae populations increased (to $56 \%$ ) during the uranium reduction phase with DO control, but declined during the ethanol limitation phase (Figure 3c). The majority of Desulfovibrionaceae clones had $98 \%$ sequence identity to Desulfo-

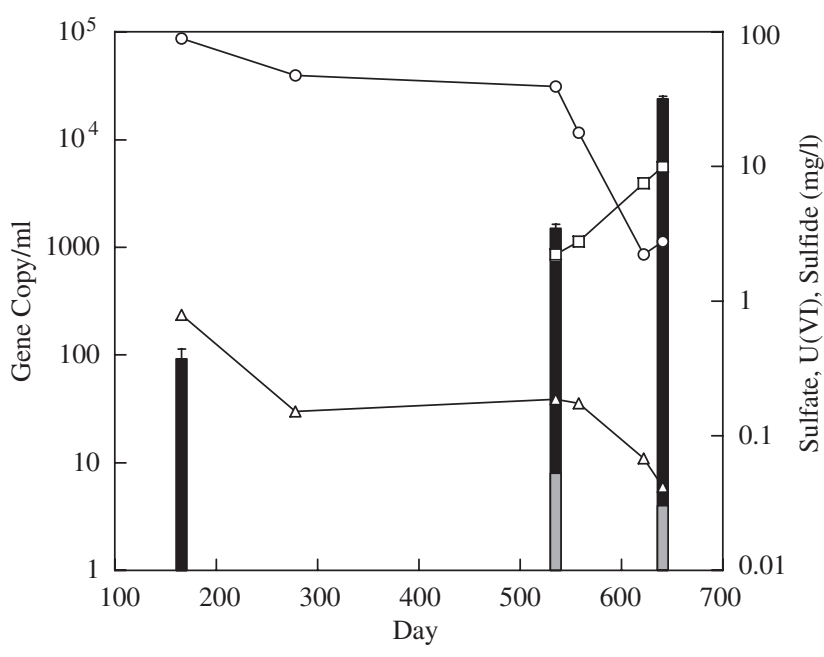

Figure 4 Gene copy number for Desulfovibrio (black bars) and Geobacter (gray bars) species based upon qPCR with conserved primers. The uranium $(\triangle)$, sulfate $(\bigcirc)$ and sulfide $(\square)$ levels over time in FW101. qPCR, quantitative PCR.

vibrio magneticus (D43994) (Figure 5). The majority of the Geobacteraceae clones had 100\% sequence identity to an uncultivated Geobacter clone (AY780563) (Figure 5). To validate these results, qPCR was used to quantify Desulfovibrio spp. and Geobacter spp. from the same samples. The qPCR results demonstrated an increase in gene copy number for Desulfovibrionaceae (Figure 4), and a similar trend for these populations correlated to the clone library analyses $\left(r^{2}=0.9\right)$.

Acidobacteria, Actinobacteria and $\alpha$-Proteobacteria populations were more consistently observed for the tested wells during the time course, whereas Firmicutes populations were detected in certain wells at certain days (Figure 3d). The highest level of $\alpha$-Proteobacteria (33\% of clones) occurred in FW024 on day 535 . The majority of $\alpha$-Proteobacteria clones had $97 \%$ sequence identity to Sphingobium herbacidovorans (EF065102) (Supplementary Figure S3). Sphingobium sequences were detected earlier at an uncontaminated background site (Fields et al., 2005)

Acidobacteria populations were detected at low levels in FW024 and FW102 at all time points. In FW101, Acidobacteria peaked on day 278 (25\% of clones) and declined thereafter (Figure $3 \mathrm{~d}$ ). The majority of the clone populations had $97 \%$ sequence identity to Geothrix fermentans (U41563) (Supplementary Figure S4). Actinobacteria populations were consistently detected and represented $7 \%$ of the clones for FW026 on day 535 and lower levels at FW024, FW104 and FW103 throughout the experiment. Changes in the Actinobacteria population were especially pronounced in FW101 and FW102 (Figure 3d). The majority of these clones had 98\% sequence identity to an uncultivated Actinobacterium clone (AJ888538) (Supplementary Figure S5). A study by Gremion et al. (2003) suggested that Actinobacteria populations were a major 


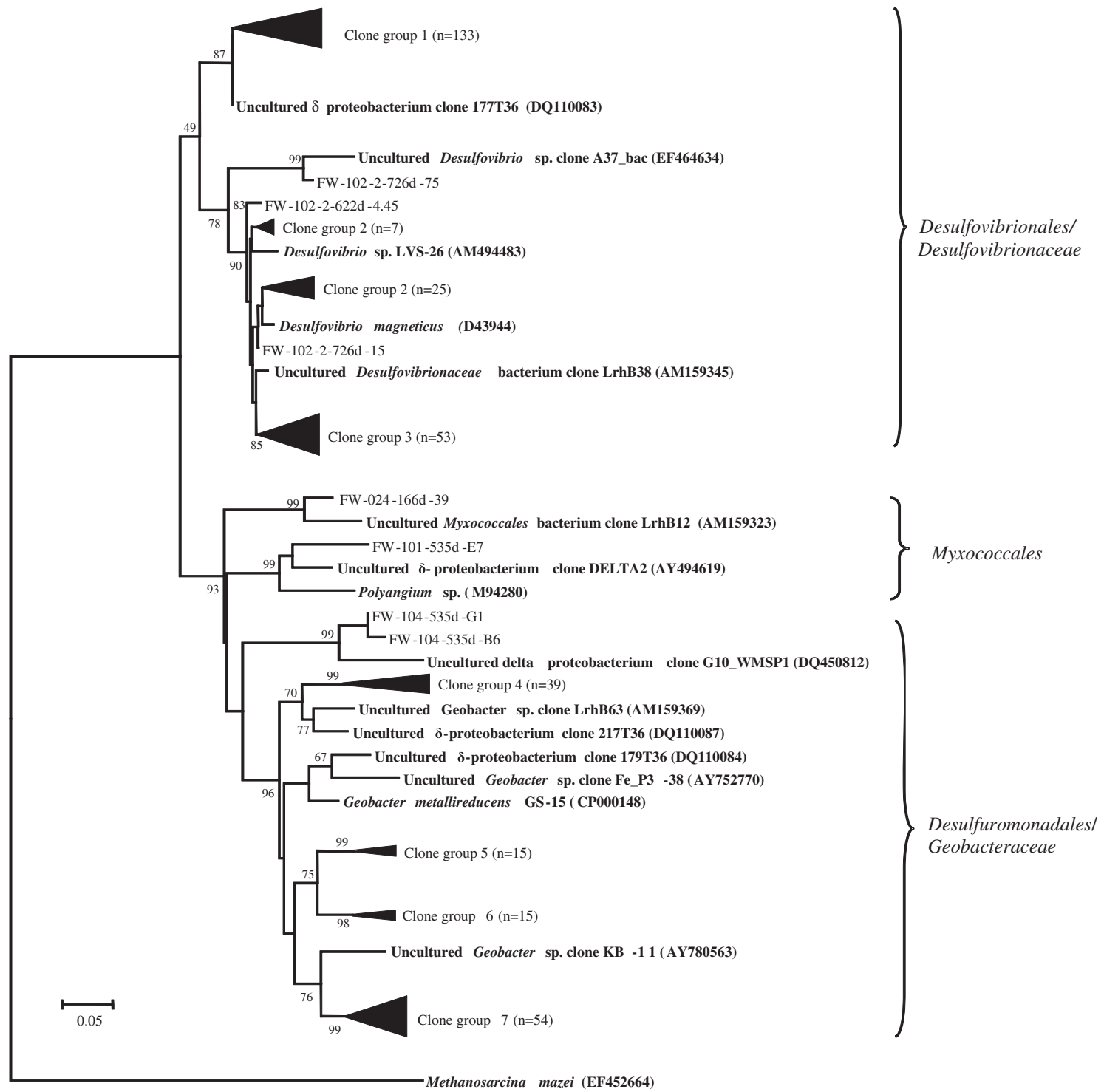

Figure 5 Phylogenetic relationship of cloned SSU rRNA genes classified in the $\delta$-Proteobacteria and reference sequences (in bold) from GenBank (accession numbers in parentheses).

metabolically active group in a heavy -metalcontaminated soil.

Firmicutes were detected at $<3 \%$ of clones between days 535 and 712 in FW104 and did not change significantly $(<5 \%$ of clones). In both FW101 and FW102, however, Firmicutes populations increased to $25 \%$ during the ethanol limitation phase (days 713-754). The clone populations of the Firmicutes family in these two wells during this phase had 96-98\% sequence identity to an uncultivated Desulfosporosinus spp. clone (AY607216) (Supplementary Figure S6).

\section{Spatial and temporal analysis of the bacterial community}

The temporal and spatial differences in the wells were further analyzed using hierarchical clustering with an UPGMA algorithm and principal coordi- nates analysis (Figures 6a and b). The three wells most affected by groundwater recirculation and ethanol addition, FW104, FW101 and FW102, clustered together on day 166, which indicated that these wells were initially similar in community composition. The up-gradient well, FW024, did not have a major shift in bacterial community structure or composition over the tested time period. Moreover, the bacterial communities in the three wells FW104, FW101 and FW102 were similar to those of FW024 on day 166 (that is, before ethanol addition), which suggested that the initial communities were similar before the treatment strategy was implemented.

FW024 on day 712 clustered with FW103 on day 747 ( $>99.9 \%$ confidence) (Figure 6a). These two wells were the outermost up- and down-gradient wells, respectively. Similarly, the two down-gradient wells, FW026 and FW103, clustered together at 
a
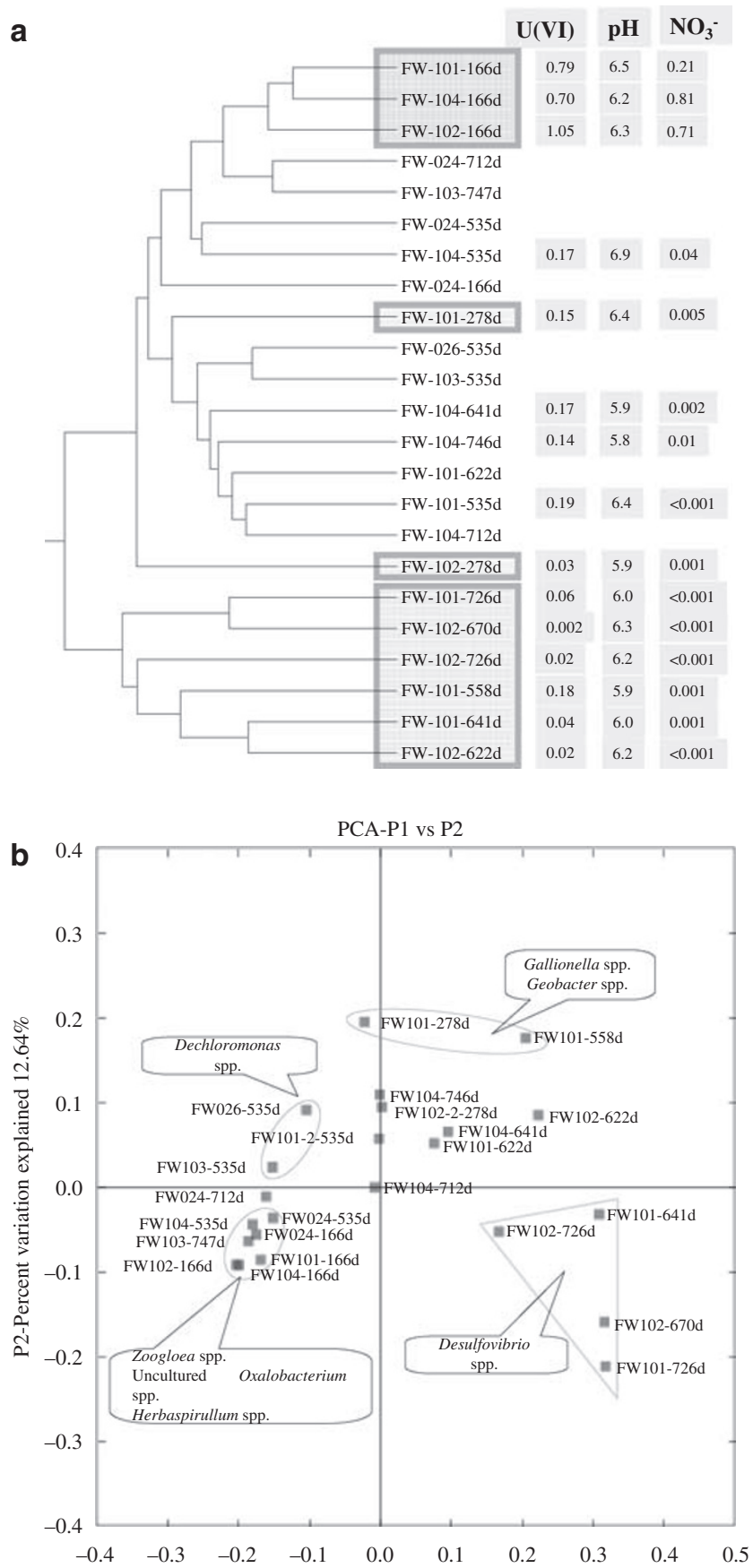

Figure 6 UniFrac statistical comparison of groundwater bacterial communities based upon phylogenetic comparisons. (a) UPGMA tree based upon UniFrac distances showing the overall phylogenetic relationships of each sampled community at a given sampling time. Nitrate, mM; U, $\mathrm{mg} \mathrm{l}^{-1}$. (b) Principal coordinate analysis (PCoA) of UniFrac distances resulted in a clustering pattern similar to that observed by UPGMA. The circled groupings indicate the bacterial communities that were grouped. Genus designations are based upon the population(s) in that community based upon lineage-specific analysis in UniFrac.

day 535 with $>99.9 \%$ support. FW101 at days 278, 535 and 622 clustered with FW104 on days 641, 712 and 746 . These data suggested that the injection well lagged in bacterial community development compared with the communities at the downgradient monitoring wells that were most directly affected by ethanol addition. Community structure for monitoring wells FW101 and FW102 clustered at days 641 and $622(90-99 \%$ confidence) and days 726 and 670 (99\% confidence). These results indicated that the bacterial communities from the wells most directly impacted by ethanol addition were altered in different ways and ultimately became more similar to one another than the other wells.

Correspondence analysis resulted in similar results to the principal coordinates analysis that clustered the inner wells (Supplementary Figure S7). In addition, lineage-specific analyses revealed that clustering at earlier time points was because of the shared presence of several denitrifying bacterial populations. Samples from FW026 and FW103 at day 535 clustered because of the shared presence of both iron-oxidizing and iron-reducing populations, and samples from the two inner bioreduction wells clustered because of the shared presence of sulfatereducing populations (Figure 6b). LIBSHUFF analyses of the injection and two biostimulation wells revealed similar results in which the bacterial communities developed changes in parallel while the injection well lagged $(P<0.001)$ (data not shown). These results indicated that the bacterial communities within treated wells diverged sharply from those in up- and down-gradient wells, and that the community changes could be correlated to changes in geochemical conditions (for example, electron acceptors) during stimulation for bioremediation.

\section{Bacterial community structure and groundwater} variable relationships

When CCA was performed based upon population distributions with time and space as the variables, treatment wells (ethanol delivery) could be easily distinguished from outer- and inner-loop wells, and injection wells and treatment wells displayed a trajectory that followed a temporal vector (data not shown). CCA identified major species-environment correlations, and F-ratios were used to determine the variance for the independent variables as described earlier (ter Braak and Smilauer, 2002). The test of significance (global permutation tests) based upon all canonical eigenvalues ranged from 0.002 to 0.04 and indicated that the relations between the species and the measured environmental variables were highly significant.

When both the bacterial community structure and physicochemical variables were compared by pCCA, with engineering controls and geochemistry as variables and spatial location as covariables, the association of FW101 and FW102 at later time points was observed (Figures 7 and 8). There was a shift in community structure between times with 


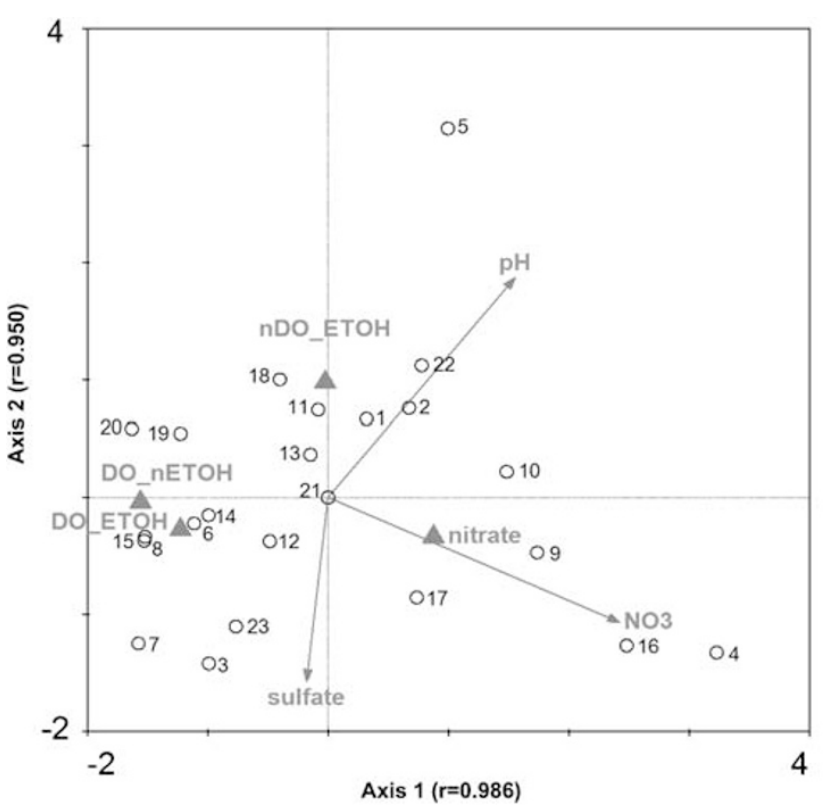

Figure 7 Ordination diagram from pCCA of \% OTUs where engineering controls (nominal variables illustrated by triangles; nDO, no DO control; ETOH, ethanol was added; DO, DO was controlled; nETOH, no ethanol. DO, dissolved oxygen.) and subsurface geochemistry (quantitative variables illustrated by arrows) were environmental variables and spatial locations were covariables. Samples are represented as open circles and the numbers correspond to the sample number ID in Tables 1 and 2. The diagram accounts for approximately $33.5 \%$ of the variance in the species data $(P=0.01)$

and without DO control, irrespective of ethanol addition. Upon examination of the inner bioreduction wells only, the pCCA suggested that environmental variables (with space as a covariable) could explain approximately $63 \%$ of the species data $(P=0.018)$ (Table 3). U(VI), nitrate, COD, sulfide and sulfate strongly associated with the shifts in bacterial community patterns, and the correlations were meaningful in a biogeochemical context (for example, nitrate decline corresponded to decline in denitrifiers; sulfide correlated to the predominance of sulfate-reducing bacteria).

At day 166, FW104, 101 and 102 had high concentrations of nitrate and uranium and the associated bacterial communities were predominated by phyla common for nitrate-reducing bacteria (for example, $\beta$-Proteobacteria and $\gamma$-Proteobacteria) (Figure 8). Proceeding in a direction opposite to the gradient for nitrate and uranium indicates a negative correlation between nitrate and uranium and other bacterial communities. By contrast, nitrate-reducing species correlated positively to increasing COD, a measure of the available ethanol. The ordination diagram indicated that patterns of bacterial community were strongly associated with the spatial and temporal differences in the geochemistry of groundwater and that these markers could represent good indicators for radionuclide reduction potential and monitoring. For clarity, higher divisions of bacterial

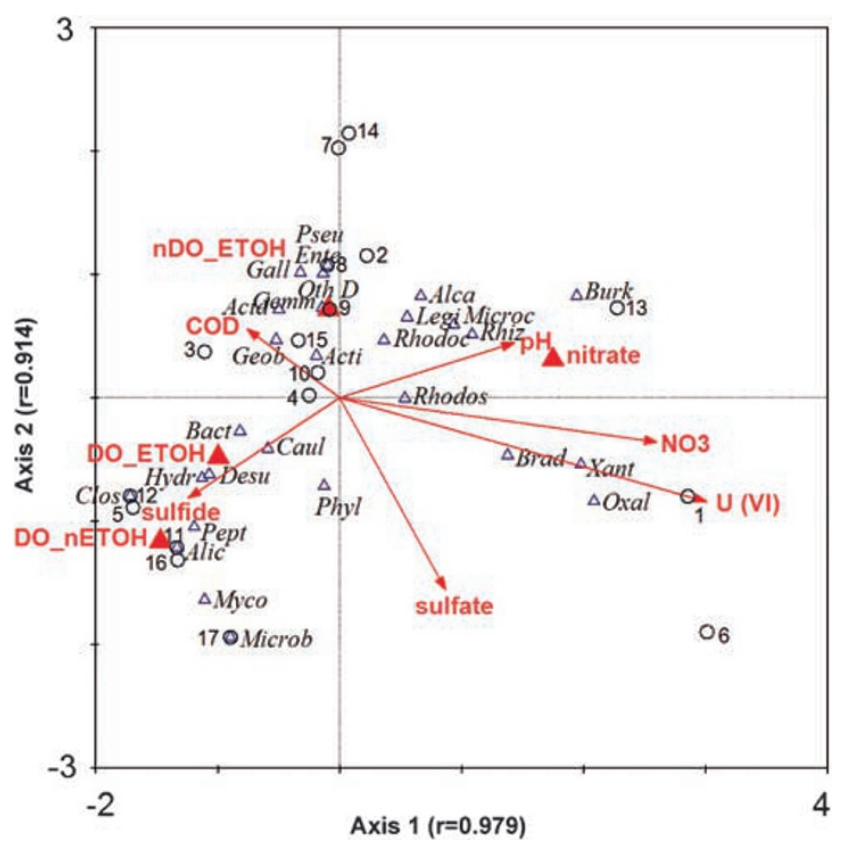

Figure 8 Ordination diagram of axes 1 and 2 of the bacterial families from the wells of the bioreduction zone where engineering controls (nominal variables illustrated by triangles) and subsurface geochemistry (quantitative variables illustrated by arrows) were environmental variables and spatial locations were covariables. 'Species' are illustrated by open triangles and the abbreviations are as follows: Oxal, Oxalobacteraceae; Brad, Bradyrhizobiaceae; Xant, Xanthomonas; Rhodos, Rhodospirillaceae; Burk, Burkholderiaceae; Rhiz, Rhizobiaceae; Alca, Alcaligenaceae; Rhodoc, Rhodocyclaceae; Oth D, Other $\delta$-Proteobacteria; Geob, Geobacteraceae; Bact, Bacteroidetes; Microb, Microbacteraceae; Hydr, Hydrogenophilaceae; Clos, Clostridiaceae; Pept, Peptococcaceae; Caul, Caulobacteraceae; Myco, Mycobacteraceae; Desu, Desulfovibrionaceae; Alic, Alicyclobacillaceae; Phyl, Phyllobacteraceae; Microc, Micrococcaceae; Legi, Legionellaceae; Acti, Actinobacteria; Acid, Acidobacteria; Gall, Gallionellaceae; Ente, Enterobacteraceae; Pseu, Pseudomonadaceae. Only bacterial families with a cumulative fit $\geqslant 5 \%$ on the first two axes are shown. Samples are illustrated by open circles and the numbers correspond to the sample ID number in Table 2. The diagram accounts for approximately $63 \%$ of the variance in the species data $(P=0.018)$

classification were used in the comparisons, and associations of particular populations could be discerned for the biostimulated wells. Thus, as the Acidobacteria, Geobacteraceae, Actinobacteria, Desulfovibrionaceae and Firmicutes populations increased, the levels of nitrate had declined and uranium declined. Desulfovibrionaceae and Firmicutes populations were also strongly associated with the sulfate (decline) and sulfide (increase) levels (Figure 8).

It is interesting to note that Acidobacteria and Geobacteraceae populations were positively correlated with higher COD levels (Figure 8). The results suggested that these populations were more prevalent when ethanol levels were higher during earlier and intermediate time points. In contrast, the sulfate reducing bacteria (SRBs) sequences (namely, Desulfovibrionaceae) predominated at later time points along with sequences for Firmicutes, 
namely Desulfosporosinus spp. and uncultivated Clostridium species (Figure 8).

Samples that had a decrease in nitrate and U(VI) levels were clustered, and the phases of DO control with and without ethanol had similar community structure and composition (Figures 7 and 8). The relationships between the samples based upon community structure and the engineering controls were also highly significant $(P<0.01)$. However, the samples that represented time points when DO control was implemented compared with no DO control (with ethanol delivery) had a shift in community structure and the associated populations were Desulfovibrio, Desulfosporosinus and Hydrogenophilaceae species as well as Bacteroidetes and Caulobacteraceae. The pCCA data also suggested that the DO control phases had similar community structure and composition independent of ethanol addition. These results indicated that stimulant levels could be decreased or stopped at least for the tested time period without major shifts in population composition or distribution.

Total variation of the species data was partitioned into six categories (Table 3). When all wells were considered, the environmental (that is, engineering controls and subsurface geochemistry) and space variables accounted for the majority of variation $(32.0 \%$ and $24.6 \%$, respectively; Figure 9). However, $36 \%$ of the biological variation was unexplained (Figure 9). When only the biostimulated wells were considered, the environmental variable could account for approximately $50.1 \%$ of the variability, and the unexplained portion of the variability was $17.3 \%$ (Figure 9).

\section{Discussion}

Diversity and community function

Microbial communities have been extensively characterized at uranium-contaminated sites (Abdelouas et al., 2000; Chang et al., 2001, 2005; Anderson et al., 2003; Elias et al., 2003; Nevin et al., 2003; Vrionis et al., 2005) including the OR-FRC (Yan et al., 2003; North et al., 2004; Fields et al., 2005, 2006; Akob et al., 2007). In general, it is assumed that bacterial diversity will depend upon the degree of contamination and will change in structure and

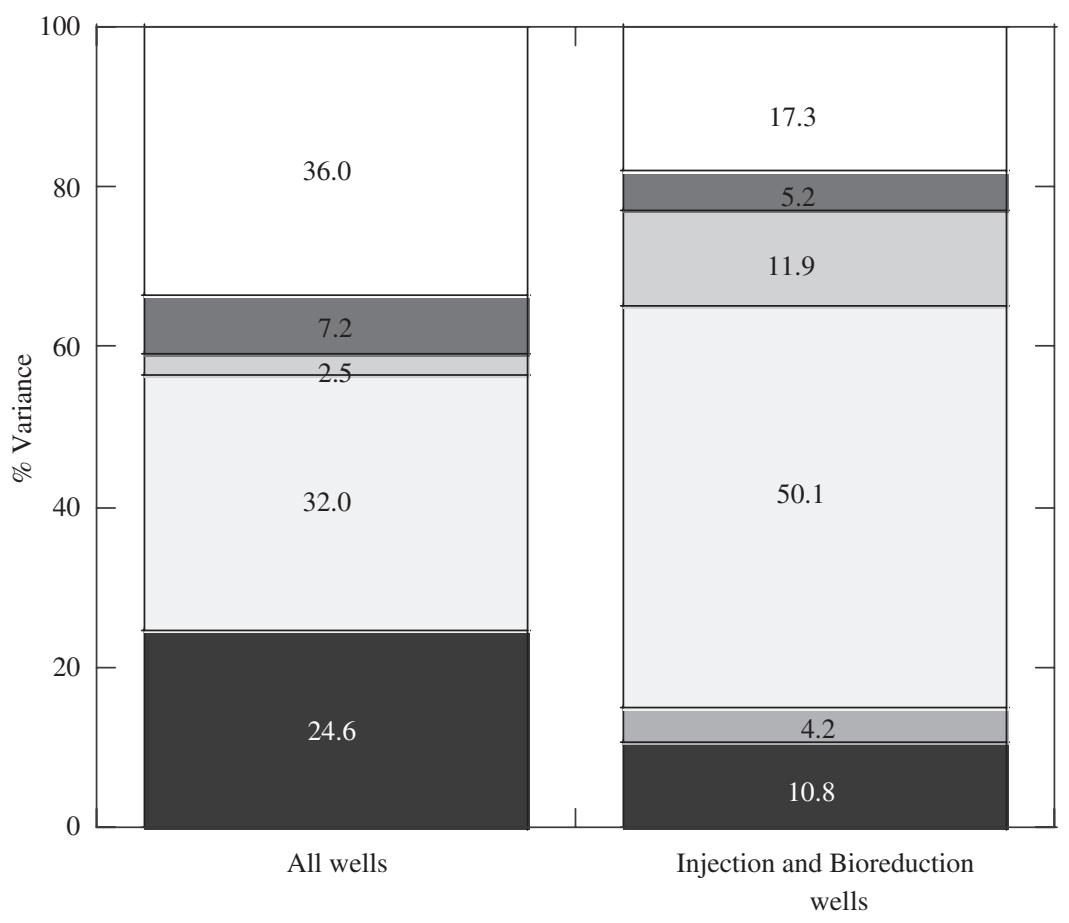

$\mathbf{\square}$ Unexplained variation
'pure' temporal variation
'shared' environmental and temporal variation
'pure' environmental variation
'shared' environmental and spatial variation
'pure' shared spatial variation

Figure 9 Partition of the total variation into six components: unexplained variation; 'pure' temporal variation; 'shared' variation between environment and time; 'pure' environmental variation; 'shared' variation between environment and space; and 'pure' spatial variation. 
composition in response to geochemical changes (for example, nutrients, $\mathrm{pH}, E_{\mathrm{h}}$ and so on). In our study, transitory trends were suggested from nitratereducing to iron-related redox metabolism to sulfatereducing populations, and these results indicated that bacteria exhibited distributions at the landscape scale in agreement with predictable geochemical factors. During biostimulation, population distributions followed geochemical parameters (that is, nitrate to iron to sulfate reduction) with spatial differences that matched the expected geochemical changes; however, the biostimulated communities displayed idiosyncratic responses during the transitions (communities were dissimilar at intermediate time points). As described by Lawton et al. (1998), the idiosyncratic theory assumes that the relationship between species richness and ecosystem function does not follow a consistent pattern. In addition, the measured variables could only account for $50 \%$ of the biological variability in the stimulated wells.

The bioreduction wells (FW101 and FW102) had different streamlines passing from the injection well and progressed differently to a common community structure dominated by sulfate-reducing bacteria. The bioreduction wells displayed a variety of responses when diversity and uranium levels were compared as a measure of ecosystem process (that is, uranium reduction), and the comparison of nitrate levels to diversity displayed a similar relationship (Table 2; data not shown). The results suggested that the population distributions depended on the particular conditions of the local environment. Further work is needed to discern the relationships between specific ecosystem processes and bacterial diversity, but this study implied that population distributions depended on the particular conditions experienced as opposed to a system that is insensitive to diversity or one in which diversity contributes to ecosystem processes in a unique but predictable fashion.

The observed increase in bacterial diversity could be attributed to the input of energy and carbon source, which allowed increased colonization. The diversity of the treatment wells increased during the greatest decline in soluble U(VI) levels but fluctuated when U(VI) levels further decreased below $0.03 \mathrm{mg} \mathrm{l}^{-1}$. The diversity increase was more likely a consequence of nutrient addition rather than the decline in U(VI) levels as uranium is not the only toxic contaminant present in the OR-FRC groundwater (Fields et al., 2006). The increase in diversity most likely altered population distributions, thereby changing the functionality of the community. It would appear that carbon/energy levels increased above a minimum level required for survival (or at least to the limit of detection) of various species. This type of response has been observed for plant diversity as productivity increases from very low levels (Huston and DeAngelis, 1994).

\section{Engineering controls}

Multivariate analytic tools are commonly used in macroecology studies to identify diversity and distribution patterns of plants and animals in relation to environmental parameters. Ramette (2007) suggested that these tools can also be readily applied in microbial ecology to help reduce data set complexity as DNA sequence data are increasingly available because of high-throughput sequencing technologies. Indeed, microbial ecology studies have increasingly used multivariate analyses to relate environmental variation with bacterial composition in aquatic systems (Yannarell and Triplett, 2005; Kent et al., 2007; Rubin and Leff, 2007), to determine bacterial community dynamics in relation to temporal variation in marine ecosystems (Pringault et al., 2007; Sapp et al., 2007), to develop microbial communities as indicators of ecosystem stress (Cao et al., 2006; Córdova-Kreylos et al., 2006; Fields et al., 2006), as well as to link geophysical signatures to microbial communities (Allen et al., 2007).

In our study, the use of pCCA enabled the identification of the crucial engineering controls with which bacterial community composition shifts appeared significantly related. We first compared bacterial community composition shifts between all wells and found that although the majority of the variation could be explained by spatial and environmental variables, a portion of the variance remained unexplained. Other ecological studies that used variance partitioning have also observed high levels of unexplained variation (Titeux et al., 2004). When we examined the bacterial community composition between the bioreduction wells only, the unexplained variation decreased. Titeux et al. (2004) suggested that the high unexplained species assemblages could be because of unaccounted factors such as the fluctuations of communities along temporal and spatial scales, unmeasured environmental variables and limitations in separating geographical factors that could be because of spatially structured processes. Our results suggested that other geochemical variables could be important indicators, and while it is difficult to measure everything, future efforts should attempt to include a range of variables to represent an even more holistic approach.

Changes in bacterial diversity were expected to result from engineering controls, and pCCA indicated that bacterial populations shifted with DO control measures and carbon/energy source additions. When ethanol was added, major shifts in sampled diversity and structure occurred, but when ethanol was withheld, DO control was needed to prevent further changes in the bacterial community. These results suggested that engineering controls impacted the development of bacterial communities with the desired metabolic activity. As pointed out by Kassen and Rainey (2004), microbiologists typically define function through mechanisms that involve genes and gene products, but a broadened perspective should include fitness of individual 
populations. Fitness could be a measure of population survival and reproduction and is an ecological measure that relates genotype interactions with biotic and abiotic variables.

Other field studies observed bacterial population shifts during short-term push-pull stimulations, which were predominated by iron-reducing populations (North et al., 2004) or a mix of sulfate-reducing and/or iron-reducing populations (Abdelouas et al., 2000; Vrionis et al., 2005), whereas others observed predominance by sulfate reducing bacteria (SRBs), namely Desulfosporosinus (Nevin et al., 2003), Desulfosporosinus and Clostridium (Suzuki et al., 2003), Desulfobacter species (Vrionis et al., 2005). Over the tested period in our study, the communities became dominated by sulfate-reducing populations closely related to Desulfovibrio species. It is likely that additional populations are directly and/ or indirectly involved in U(VI) bioreduction at this site, and it will become increasingly important to develop more sensitive molecular techniques as well as more robust cultivation methods to better understand remediation strategies.

\section{Biotic associations}

Similar to previous studies, we observed nitrate to be a major factor that influenced U(VI) reduction. After nitrate removal, a major shift in bacterial communities was observed with continued ethanol additions. Community structure first transitioned to nitrate reducing and then to populations of iron oxidizers (Gallionella ferruginea) and iron reducers (Geothrix spp., Geobacter spp., Holophaga spp.). $G$. ferruginea is able to live in low-oxygen conditions (Anderson and Pedersen, 2003) and has been found in many acidic metal-rich waters (Kim et al., 2002; Bruneel et al., 2006; Hallberg et al., 2006). Geothrix spp. have been isolated from a hydrocarbon-contaminated aquifer (Coates et al., 1999) and were also enriched when exposed to petroleum compounds in laboratory experiments (Abed et al., 2002). Geothrixlike sequences were also detected in the stimulated treatment zones of FRC sediments (Cardenas et al., 2008). Geobacter spp. have been found in metalpolluted freshwaters (Cummings et al., 2003) and detected in high numbers at sites treated for U(VI) remediation (Holmes et al., 2002; Anderson et al., 2003). The metabolic potential of iron-oxidizing and iron-reducing populations could have further implications on the stability of U(VI) immobilization as iron-oxidizing populations can potentially re-oxidize U(IV) and/or oxidize Fe(II) in a nitrate-dependent manner. The dynamics between iron oxidizers, iron reducers and sulfate reducers warrants further investigation at contaminated field sites.

Geobacter sequences were observed throughout the experiment but were highest when COD levels (that is, organic carbon) were elevated. The Geobacter populations appeared to associate with Acidobacteria populations (for example, Geotherix spp., and Holophaga spp.), but the nature of the possible interactions between these populations is unknown. Further work is needed to examine possible direct or indirect interactions. It is not known whether niche complementarity would lead to greater stability in bioremediation processes although studies have shown that it can explain positive relationships between diversity and function in prairie grasslands (Tilman et al., 1996).

Diverse Acidobacteria have been detected in different uranium-contaminated sites (Barns et al., 2007); however, little is known regarding physiology or ecology. The abundance of Acidobacteria in groundwater suggested an ability to tolerate high levels of metal and nitrate contamination, but the data also indicated that the Acidobacteria did not continue to compete with sulfate- and metal-reducing populations. Further analysis by pCCA revealed that the prevalence of Geobacter and Acidobacteria populations was more strongly correlated to the availability of ethanol rather than low U(VI) levels. These results emphasized the importance of a better understanding of population interactions leading to competition and/or mutually beneficial use of nutrient and energy sources.

In terms of the ecosystem process of interest in our study, multiple species could be classified into the same 'functional group' (that is, heavy metal reduction). For instance, both iron and sulfate reducers could be considered at least partially substitutable with respect to contribution to the ecosystem process of interest (that is, U(VI) reduction); however, iron and sulfate reducers can be very different organisms with respect to biogeochemistry and community interactions. Different studies have demonstrated the utility and predominance of iron and sulfate reducers at respective sites. Further work is still needed to determine how environmental conditions can be controlled at respective sites to optimize community structure, diversity and function within the context of desired ecosystem processes.

When DO control measures were compared with community composition, the results suggested that Geobacter spp. were more oxygen tolerant, as the populations were detected at higher levels when DO was not being controlled and that Desulfovibrio spp. were able to adapt to more anoxic conditions. An alternative explanation might be an interaction between Geobacter and an oxygen-tolerant microorganism. However, as mentioned earlier, the COD levels were also higher when DO was not specifically controlled. Separate studies at the OR-FRC showed that metal-reducing populations such as Geobacter spp. and Anaeromyxobacter spp. predominated in contaminated sediments following in situ biostimulation of microbial populations during push-pull tests (Petrie et al., 2003; North et al., 2004; Michalsen et al., 2007). However, different electron donors and engineering controls were used, and these comparisons also support the notion that 
there is an idiosyncratic relationship between population distribution and ecosystem process in terms of biostimulation for heavy metal reduction. As ethanol was being limited, Firmicutes were detected at increasing levels in groundwater and were especially pronounced in FW102. The Firmicutes sequences were closely related to the fermenting bacteria, Clostridium spp., the sulfate-reducing, Desulfosporosinus spp., and other sequences closely related to the Peptococcaceae family.

Research has shown that both Clostridium spp. and Desulfosporosinus spp. can be stimulated in uranium mine sediments (Suzuki et al., 2003) and Desulfosporosinus spp. have also been enriched in high-salinity subsurface sediment stimulated for U(VI) reduction (Nevin et al., 2003), as well as heavy metal column experiments (Geets et al., 2006). Clostridium spp. were shown to be able to reduce U(VI) (Francis et al., 1994; Madden et al., 2007) and similar populations were also detected in other OR-FRC sediments using glycerol-amended enrichments (Petrie et al., 2003). Clostridium populations were also suggested to be active members of the OR-FRC microbial community through a study of RNA-derived clone libraries (Akob et al., 2007), and low $-\mathrm{G}+\mathrm{C}$ bacteria have been isolated from OR-FRC groundwater (Fields et al., 2005).

pCCA analysis indicated that bacterial communities were similar in the DO control phases regardless of electron donor availability. Indeed, Desulfovibrio populations were still predominant during this phase despite the fact that the subsurface condition may have started to favor fermentative metabolism by Firmicutes. The presence of populations that have both sulfate- and metal-reducing capabilities at the later phases of our study suggested a potential for continued uranium reduction during the periods when soluble electron donor is not provided. This was further observed by pCCA in which Firmicutes and Desulfovibrio populations were negatively correlated with U(VI) levels.

Although microbial communities adsorbed in the sediments can be significantly different from the planktonic populations in the aquifer, a recent study that characterized sediments at day 774 showed that Desulfovibrio spp. were the most abundant genus in the biostimulated zone (Cardenas et al., 2008), and our results with groundwater also showed a predominance of Desulfovibrio sequences at this time period. The Cardenas et al. (2008) study also detected Desulfosporosinus, Geobacter, Anaeromyxobacter, Geothrix and Acidovorax related sequences associated with the sediment, and similar sequences were detected in our temporal study of the groundwater albeit at different proportions. These results suggested that some predominant populations might inhabit both the solid and aqueous phases (for example, Desulfovibrio), whereas others might be exclusive to solid phases (for example, Acidobacteriaceae). In the case of this test site, Desulfovibrio sequences predominated in both the sediments and groundwater; however, it is not known whether the predominance of the same putative population(s) in the solid and aqueous phases would be unique to an engineered site and/or dependent upon the existing community composition. Although not the focus of this study, future work is needed to discern the importance and functionality of surface-adhered versus aqueous-phase communities.

\section{Conclusion}

The development of certain bacterial populations corresponded to the manipulated groundwater geochemical variables and showed that it is possible to stimulate the desired function in an engineered system. In terms of U(VI) immobilization, the wells responded differently, but prolonged engineering controls were able to stimulate growth of bacterial communities with the desired U(VI) reduction capacity. The notion of niche development through the application of selective pressures provides a possible framework for use of molecular ecology to improve process performance. Questions remain about how diversity and stability are related in terms of biochemical function, whether all in situ engineered systems would behave similarly, and whether the niche exclusion and selection concepts can be applied to improve models of active transport.

\section{Acknowledgements}

We thank Dr A Konopka for comments and discussions and Dr MB Leigh for comparison with unpublished data. We also thank the comments of the anonymous reviewers. This study and the Virtual Institute for Microbial Stress and Survival are supported by the US Department of Energy, Office of Biological and Environmental Research, Genomics:GTL program through contract DE-AC0205CH11231 between Lawrence Berkeley National Laboratory and the US Department of Energy. Partial funding was also provided under grant DOEAC05-00OR22725. Sequence determination was enhanced through an NSFMRI equipment grant to Miami University (NSF 0420479).

\section{References}

Abdelouas A, Lutze W, Gong W, Nuttall EH, Strietelmeier BA, Travis BJ. (2000). Biological reduction of uranium in groundwater and subsurface soil. Sci Total Environ 250: 21-35.

Abed RM, Safi NM, Köster J, de Beer D, El-Nahhal Y, Rullkötter J et al. (2002). Microbial diversity of a heavily polluted microbial mat and its community changes following degradation of petroleum compounds. Appl Environ Microbiol 68: 1674-1683.

Akob DM, Mills HJ, Kostka JE. (2007). Metabolically active microbial communities in uranium-contaminated subsurface sediments. FEMS Microbiol Ecol 59: 95-107. 
Allen JP, Atekwana EA, Atekwana EA, Duris JW, Werkema DD, Rossbach S. (2007). The microbial community structure in petroleum-contaminated sediments correspond to geophysical signatures. Appl Environ Microbiol 73: 2860-2870.

Anderson CR, Pedersen K. (2003). In situ growth of Gallionella biofilms and partitioning of lanthanides and actinides between biological material and ferric oxyhidroxides. Geobiology 1: 169-178.

Anderson MJ, Gribble NA. (1998). Partitioning the variation among spatial, temporal and environmental components in a multivariate data set. Austral Ecol 23: $158-167$.

Anderson MJ, Willis TJ. (2003). Canonical analysis of principal coordinates: a useful method of constrained ordination for ecology. Ecology 84: 511-525.

Anderson RT, Vrionis HA, Ortiz-Bernad I, Resch CT, Long PE, Dayvault R et al. (2003). Stimulating the in situ activity of Geobacter species to remove uranium from the groundwater of a uranium-contaminated aquifer. Appl Environ Microbiol 69: 5884-5891.

Barns SM, Cain EC, Sommerville L, Kuske CR. (2007). Acidobacteria phylum sequences in uranium-contaminated subsurface sediments greatly expand the known diversity within the phylum. Appl Environ Microbiol 73: 3113-3116.

Brown MV, Bowman JP. (2001). A molecular phylogenetic survey of sea-ice microbial communities (SIMCO). FEMS Microbiol Ecol 35: 267-275.

Bruneel O, Duran R, Casiot C, Elbaz-Poulichet F, Personné JC. (2006). Diversity of microorganisms in Fe-As-rich acid mine drainage waters of Carnoulès, France. Appl Environ Microbiol 72: 551-556.

Cao Y, Cherr GN, Córdova-Kreylos AL, Fan TW, Green PG, Higashi RM et al. (2006). Relationships between sediment microbial communities and pollutants in two California salt marshes. Microb Ecol 52: 619-633.

Cardenas E, Wu WM, Leigh MB, Carley J, Carroll S, Gentry $\mathrm{T}$ et al. (2008). Microbial communities in contaminated sediments after bioremediation to submicromolar levels. Appl Environ Microbiol 74: 3718-3729.

Chang YJ, Long PE, Geyer R, Peacock AD, Resch CT, Sublette K et al. (2005). Microbial incorporation of 13C-labeled acetate at the field scale: detection of microbes responsible for reduction of U(VI). Environ Sci Technol 39: 9039-9048.

Chang YJ, Peacock AD, Long PE, Stephen JR, McKinley JP, Macnaughton SJ et al. (2001). Diversity and characterization of sulfate-reducing bacteria in groundwater at a uranium mill tailings site. Appl Environ Microbiol 67: 3149-3160.

Coates JD, Ellis DJ, Gaw CV, Lovley DR. (1999). Geothrix fermentans gen. nov., sp. nov., a novel Fe(III)-reducing bacterium from a hydrocarbon-contaminated aquifer. Int J Syst Bacteriol 49: 1615-1622.

Cole JR, Chai B, Marsh TL, Farris RJ, Wang Q, Kulam SA et al. (2003). The ribosomal database project (RDP-II): previewing a new autoaligner that allows regular updates and the new prokaryotic taxonomy. Nucleic Acids Res 31: 442-443.

Córdova-Kreylos AL, Cao Y, Green PG, Hwang HM, Kuivila KM, Lamontagne MG et al. (2006). Diversity, composition, and geographical distribution of microbial communities in California salt marsh sediments. Appl Environ Microbiol 72: 3357-3366.

Craft ES, Abu-Qare AW, Flaherty MM, Garofolo MC, Rincavage HL, Abou-Donia MB. (2004). Depleted and natural uranium: chemistry and toxicological effects. J Toxicol Environ Health B Crit Rev 7: 297-317.

Cummings DE, Snoeyenbos-West OL, Newby DT, Niggemyer AM, Lovley DR, Achenbach LA et al. (2003). Diversity of Geobacteraceae species inhabiting metalpolluted freshwater lake sediments ascertained by $16 \mathrm{~S}$ rDNA analyses. Microb Ecol 46: 257-269.

Elias DA, Krumholz LR, Wong D, Long PE, Suflita JM. (2003). Characterization of microbial activities and U reduction in a shallow aquifer contaminated by uranium mill tailings. Microb Ecol 46: 83-91.

Fields MW, Bagwell CE, Carroll SL, Yan T, Liu X, Watson DB et al. (2006). Phylogenetic and functional biomarkers as indicators of bacterial community responses to mixed-waste contamination. Environ Sci Technol 40: 2601-2607.

Fields MW, Yan T, Rhee SK, Carroll SL, Jardine PM, Watson DB et al. (2005). Impacts on microbial communities and cultivable isolates from groundwater contaminated with high levels of nitric acid-uranium waste. FEMS Microbiol Ecol 53: 417-428.

Fite A, Macfarlane GT, Cummings JH, Hopkins MJ, Kong SC, Furrie E et al. (2004). Identification and quantitation of mucosal and faecal Desulfovibrios using real-time polymerase chain reaction. Gut 53: $523-529$

Francis AJ, Dodge CJ, Lu F, Halada GP, Clayton CR. (1994). XPS and XANES studies of uranium reduction by Clostridia sp. Environ Sci Tehcnol 28: 636-639.

Geets J, Vanbroekhoven K, Borremans B, Vangronsveld J, Diels L, van der Lelie D. (2006). Column experiments to assess the effects of electron donors on the efficiency of in situ precipitation of $\mathrm{Zn}, \mathrm{Cd}$, Co and $\mathrm{Ni}$ in contaminated groundwater applying the biological sulfate removal technology. Environ Sci Pollut Res Int 13: 362-378.

Gremion F, Chatzinotas A, Harms H. (2003). Comparative $16 \mathrm{~S}$ rDNA and 16S rRNA sequence analysis indicates that Actinobacteria might be a dominant part of the metabolically active bacteria in heavy metal-contaminated bulk and rhizosphere soil. Environ Microbiol 5: 896-907.

Hallberg KB, Coupland K, Kimura S, Johnson DB. (2006). Macroscopic streamer growths in acidic, metal-rich mine waters in north Wales consist of novel and remarkably simple bacterial communities. Appl Environ Microbiol 72: 2022-2030.

Holmes DE, Finneran KT, O’Neil RA, Lovley DR. (2002). Enrichment of members of the family Geobacteraceae associated with stimulation of dissimilatory metal reduction in uranium-contaminated aquifer sediments. Appl Environ Microbiol 68: 2300-2306.

Huber T, Faulkner G, Hugenholtz P. (2004). Bellerophon: a program to detect chimeric sequences in multiple sequence alignments. Bioinformatics 20: 2317-2319.

Huston MA, DeAngelis DL. (1994). Competition and coexistence: the effects of resource transport and supply rates. Am Nat 144: 954-977.

Hwang C, Wu WM, Gentry TJ, Carley J, Carroll SL, Schadt $\mathrm{C}$ et al. (2006). Changes in bacterial community structure correlate with initial operating conditions of a field-scale denitrifying fluidized bed reactor. Appl Microbiol Biotechnol 71: 748-760.

Iwamoto T, Nasu M. (2001). Current bioremediation practice and perspective. J Biosci Bioeng 92: 1-8.

Kassen R, Rainey PB. (2004). The ecology and genetics of microbial diversity. Ann Rev Microbiol 58: 207-231. 
Kent AD, Yannarell AC, Rusak JA, Triplett EW, McMahon KD. (2007). Synchrony in aquatic microbial community dynamics. ISME J 1: 38-47.

Kim JJ, Kim SJ, Tazaki K. (2002). Mineralogical characterization of microbial ferrihydrite and schwertmannite and non-biogenic Al-sulfate precipitates from acidmine drainage in the Donghae mine area, Korea. Environ Geol 42: 19-31.

Lawton JH, Naeem S, Thompson LJ, Hector A, Crawley MJ. (1998). Biodiversity and ecosystem function: getting the Ecotron experiment in its correct context. Funct Ecol 12: 848-852.

Lloyd JR. (2003). Microbial reduction of metals and radionuclides. FEMS Microbiol Rev 27: 411-425.

Lozupone CA, Hamady M, Kelley ST, Knight R. (2007). Quantitative and qualitative beta diversity measures lead to different insights into factors that structure microbial communities. Appl Environ Microbiol 73: 1576-1585.

Luo J, Wu W, Fienen MN, Jardine PM, Mehlhorn TL, Watson DB et al. (2006). A nested-cell approach for in situ remediation. Ground Water 44: 266-274.

Luo J, Wu WM, Carley J, Ruan C, Gu B, Jardine PM et al. (2007). Hydraulic performance analysis of a multiple injection-extraction well system. J Hydrol 336: 294-302.

Madden AS, Smith AC, Balkwill DL, Fagan LA, Phelps TJ. (2007). Microbial uranium immobilization independent of nitrate reduction. Environ Microbiol 9: 2321-2330.

Michalsen MM, Peacock AD, Spain AM, Smithgal AN, White DC, Sanchez-Rosario Y et al. (2007). Changes in microbial community composition and geochemistry during uranium and technetium bioimmobilization. Appl Environ Microbiol 73: 5885-5896.

Muylaert K, Sabbe K, Vyverman W. (2000). Spatial and temporal dynamics of phytoplankton communities in a freshwater tidal estuary (Schelde, Belgium). Estuar Coast Shelf Sci 50: 673-678.

Nevin KP, Finneran KT, Lovley DR. (2003). Microorganisms associated with uranium bioremediation in a high-salinity subsurface sediment. Appl Environ Microbiol 69: 3672-3675.

North NN, Dollhopf SL, Petrie L, Istok JD, Balkwill DL, Kostka JE. (2004). Change in bacterial community structure during in situ biostimulation of subsurface sediment cocontaminated with uranium and nitrate. Appl Environ Microbiol 70: 4911-4920.

Palmer MW. (1993). Putting things in even better order: the advantages of canonical correspondence analysis. Ecology 74: 2215-2230.

Petrie L, North NN, Dollhopf SL, Balkwill DL, Kostka JE. (2003). Enumeration and characterization of iron(III)reducing microbial communities from acidic subsurface sediments contaminated with uranium(VI). Appl Environ Microbiol 69: 7467-7479.

Pringault O, Duran R, Jacquet S, Torréton JP. (2007). Temporal variations of microbial activity and diversity in marine tropical sediments (New Caledonia Lagoon). Microb Ecol 55: 247-258.

Ramette A. (2007). Multivariate analyses in microbial ecology. Minireview. FEMS Microbiol Ecol 62: 142-160.

Rubin MA, Leff LG. (2007). Nutrients and other abiotic factors affecting bacterial communities in an Ohio River (USA). Microb Ecol 54: 374-383.
Sapp M, Wichels A, Wiltshire KH, Gerdts G. (2007). Bacterial community dynamics during the winterspring transition in the North Sea. FEMS Microbiol Ecol 59: 622-637.

Schloss PD, Handelsman J. (2005). Introducing DOTUR, a computer program for defining operational taxonomic units and estimating species richness. Appl Environ Microbiol 71: 1501-1506.

Suzuki Y, Kelly SD, Kemner KM, Banfield JF. (2003). Microbial populations stimulated for hexavalent uranium reduction in uranium mine sediment. Appl Environ Microbiol 69: 1337-1346.

Tamura K, Dudley J, Nei M, Kumar S. (2007). MEGA4: molecular evolutionary genetics analysis (MEGA) software version 4.0. Mol Biol Evol 24: 1596-1599.

ter Braak CJF, Smilauer P. (2002). CANOCO Reference Manual and CanoDraw for Windows Users Guide: Software for Canonical Community Ordination (v. 4.5). Microcomputer Power: Ithaca, NY.

Thompson JD, Higgins DG, Gibson TJ. (1994). CLUSTAL W: improving the sensitivity of progressive multiple sequence alignment through sequence weighting, position-specific gap penalties and weigh matrix choice. Nucleic Acids Res 22: 4673-4680.

Tilman D, Wedin D, Knops J. (1996). Productivity and sustainability influenced by biodiversity in grassland ecosystems. Nature 379: 718-720.

Titeux N, Dufrene M, Jacob JP, Paquay M, Defourny P. (2004). Multivariate analysis of a fine-scale breeding bird atlas using a geographical information system and partial canonical correspondence analysis: environmental and spatial effects. J Biogeogr 31: 1841-1856.

Vrionis HA, Anderson RT, Ortiz-Bernad I, O’Neill KR, Resch CT, Peacock AD et al. (2005). Microbiological and geochemical heterogeneity in an in situ uranium bioremediation field site. Appl Environ Microbiol 71: 6308-6318.

Wu WM, Carley J, Fienen M, Mehlhorn T, Lowe K, Nyman J et al. (2006a). Pilot-scale in situ bioremediation of uranium in a highly contaminated aquifer 1: conditioning of a treatment zone. Environ Sci Technol 40: 3978-3985.

Wu WM, Carley J, Gentry T, Ginder-Vogel MA, Fienen M, Mehlhorn $\mathrm{T}$ et al. (2006b). Pilot-scale in situ remediation of uranium in a highly contaminated aquifer.2. Reduction of U(VI) and geochemical control of U(VI) bioavailability. Environ Sci Technol 40: 3986-3995.

Wu WM, Carley J, Luo J, Ginder-Vogel MA, Cardenas E, Leigh MB et al. (2007). In situ bioreduction of uranium (VI) to submicromolar levels and reoxidation by dissolved oxygen. Environ Sci Technol 41: 5716-5723.

Yan T, Fields MW, Wu L, Zu Y, Tiedje JM, Zhou J. (2003). Molecular diversity and characterization of nitrite reductase gene fragments (nirK and nirS) from nitrateand uranium-contaminated groundwater. Environ Microbiol 5: 13-24.

Yannarell AC, Triplett EW. (2005). Geographic and environmental sources of variation in lake bacterial community composition. Appl Environ Microbiol 71: 227-239.

Zhou J, Bruns MA, Tiedje JM. (1996). DNA recovery from soils of diverse composition. Appl Environ Microbiol 62: $316-322$.

Supplementary Information accompanies the paper on The ISME Journal website (http://www.nature.com/ismej) 